Phase II Final Report • December 1999

\title{
NITROGEN REMOVAL FROM NATURAL GAS: Phase II
}

Prepared by:

David C. Bomberger, John L. Bomben, Arash Amirbahman, and Marianne Asaro

Prepared for:

Federal Energy Technology Center

AAD Document Control

U.S. Department of Energy

P.O. Box 10940, MS 921-143

Pittsburgh, PA 15236

Contract Number: DE-AC21-95MC32265

SRI Project 7503 
Phase II Final Report • December 1999

\section{NITROGEN REMOVAL FROM NATURAL GAS: Phase II}

Prepared by:

David C. Bomberger, John L. Bomben, Arash Amirbahman, and Marianne Asaro

SRI International

333 Ravenswood Avenue

Menlo Park, CA 94025-3493

Contract Number: DE-AC21-95MC32265

SRI Project 7503

December 1996 - December 1999

Prepared for:

Federal Energy Technology Center

AAD Document Control

U.S. Department of Energy

P.O. Box 10940, MS 921-143

Pittsburgh, PA 15236 


\section{DISCLAIMER}

This report was prepared as an account of work sponsored by an agency of the United States Government. Neither the United States Government nor any agency thereof, nor any of their employees, makes any warranty, express or implied, or assumes any legal liability or responsibility for the accuracy, completeness, or usefulness of any information, apparatus, product, or process disclosed, or represents that its use would not infringe privately owned rights. Reference herein to any specific commercial product, process, or service by the trade name, trademark, manufacturer, or otherwise does not necessarily constitute or imply its endorsement, recommendation, or favoring by the United States Government or any agency thereof. The views and opinions of authors expressed herein do not necessarily state or reflect those of the United States Government or any agency thereof.

Available to the public from the National Technical Information Service, U.S. Department of Commerce, 5285 Port Royal Road, Springfield, VA 22161; phone orders accepted at (703) 487-4650. 


\begin{abstract}
SRI identified (bis)tricyclohexylphosphine molybdenum tricarbonyl as a candidate component in an absorption system for upgrading substandard natural gas to pipeline standards by removing nitrogen. The molybdenum compound reacted selectively with nitrogen to form a complex that precipitated from solution and could be regenerated with heat and/or vacuum. The absorption system was tested in a bench scale apparatus that was designed to eliminate exposure to oxygen and water. The tests demonstrated that the absorption concept was sound, but they could not demonstrate regeneration and recycle of the molybdenum compound. The failure resulted from two causes. First, the size of the precipitated complex with nitrogen could not be controlled, and this meant that the filtration system designed for the bench scale unit either did not collect the precipitate, or blocked too quickly. Second, the molybdenum compound degraded more rapidly than was expected, and it could not be determined if this was due to intrinsic instability or inadequate control of water and oxygen exposure. An economic analysis of a full-scale process, which assumed the filtration problem could be solved, indicated that it could be competitive with existing nitrogen removal technology if a molybdenum compound lifetime of 5 years could be achieved.
\end{abstract}




\section{CONTENTS}

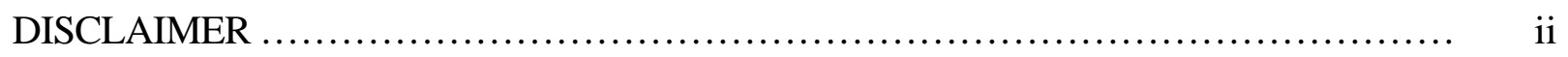

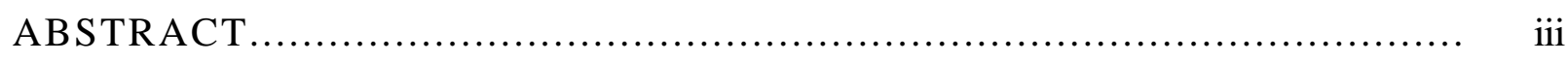

EXECUTIVE SUMMARY .........................................................

INTRODUCTION ....................................................................

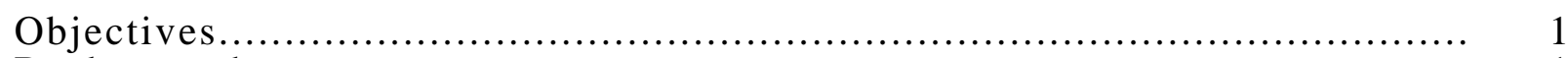

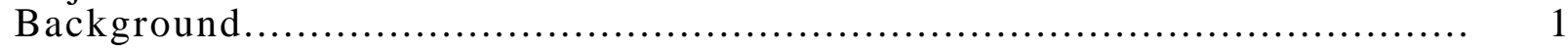

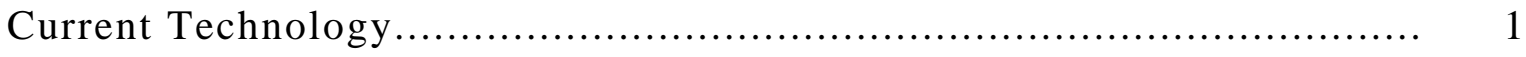

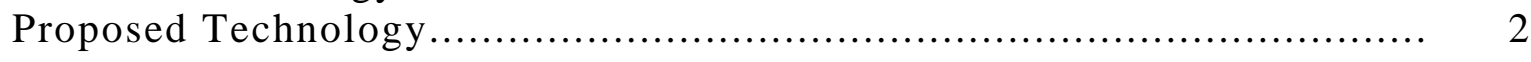

RESULTS AND DISCUSSION ...................................................... 4

Proposed Continuous Operation of Bench-Scale Apparatus..................................... 4

High Pressure Blank Tests with Pure Toluene.............................................. 7

High Pressure Experiments with Mo Phosphine Complex..................................... 10

Preparation of Phosphine Complex for Bench Scale Experiments........................ 10

Determining the Correct Pore Size of the Membrane Filter................................... 15

Apparatus Clean-Up ....................................................... 17

Absorption Experiments......................................................... 17

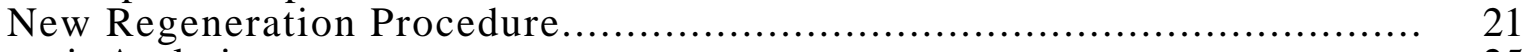

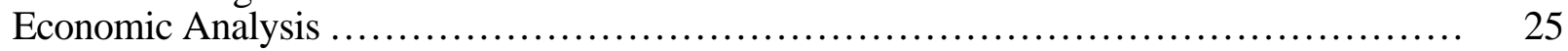

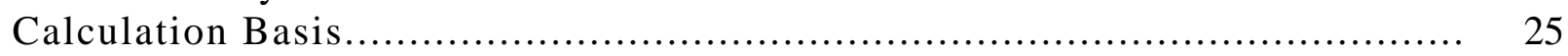

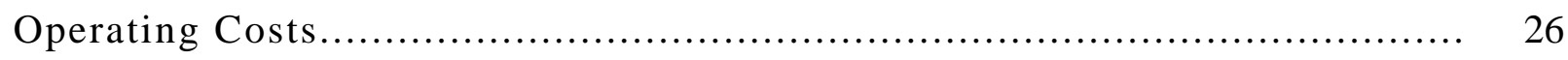

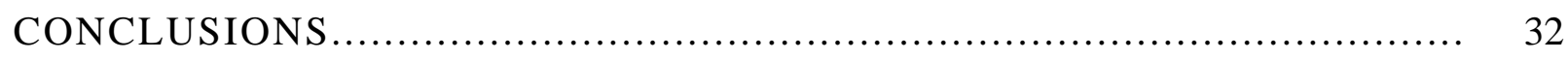

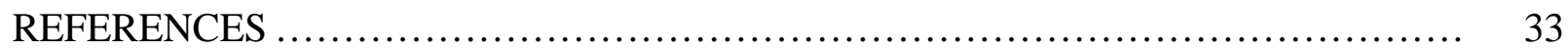

\section{APPENDICES}

A DESIGN CALCULATIONS

B DATA FROM THE HIGH-PRESSURE NITROGEN ABSORPTION EXPERIMENTS USING MOLYBDENUM PHOSPHINE COMPLEX

C GAS CHROMATOGRAPH PARAMETERS AND SAMPLE CHROMATOGRAM 


\section{EXECUTIVE SUMMARY}

The objective of Phase II of this project was to design, construct, and operate a high pressure bench-scale nitrogen absorption apparatus for removing nitrogen from subquality natural gas to meet pipeline specifications. Our conceptual process design was based on the contact between $\mathrm{N}_{2}$ and the organometallic complex solution previously selected. In Phase I of this project, we screened complexing agents in terms of their binding capacity and reversibility, and we established certain criteria for screening the nitrogen complexing agents. Based on the above criteria, (bis)tricyclohexylphosphine molybdenum tricarbonyl was selected. The molybdenum phosphine complex bound readily to $\mathrm{N}_{2}$ molecules, forming a yellow precipitate.

In our designed apparatus, an absorber is used to contact the natural gas and the phosphine complex such that the gas leaving the absorber contains less than $4 \% \mathrm{~N}_{2}$ and the liquid leaving the absorber contains the precipitated $\mathrm{N}_{2}$ bound complex, which is then filtered out. The filtrate is the lean-phosphine complex, which is sent to a holding tank. The filter cake contains the bound complex, which is regenerated by depressurization and heating. The regenerated complex is then pumped to an empty feed tank where it is mixed with the lean-phosphine pumped from the holding tank to yield a fresh molybdenum complex solution.

Our experiments demonstrated that the concept of using an absorptive complex was sound. A toluene solution of the phosphine complex could be circulated through the absorber column and showed nitrogen uptake that exceeded the uptake predicted for toluene alone. However, we encountered the following difficulties throughout the high-pressure nitrogen absorption tests that may be related to the design of the bench-scale unit and the complex itself:

(1) The molybdenum complex solids $(>12 \mu \mathrm{m})$ were apparently larger than the $\mathrm{N}_{2}$ bound precipitates, which forced a design for the regeneration system that let most of the bound complex pass through unregenerated.

(2) The small size of the bench-scale system and its components resulted in the hold up of bound complex, which in turn prevented its regeneration.

(3) The phosphine complex degraded during the adsorption experiments. It is not known whether this is an intrinsic instability or the result of exposure to air during manipulations.

(4) Synthesizing the complex was harder than anticipated, which limited the number of experiments required for collecting adequate data.

An economic analysis performed on this technology showed that the operating costs for removing nitrogen from natural gas with existing technology are \$1.0 to \$3.0/M SCF at a small 
scale (1-2 MM SCFD) and \$0.30/M SCF at a larger scale (75 MM SCFD). Operating cost estimates for nitrogen removal using the phosphine complex showed that, even if the phosphine compound lifetime were as short as 3 months, the absorption technology could be cost competitive for small plants, since the estimated operating cost was $\$ 1.70 / \mathrm{M} \mathrm{SCF}$. For larger plants, a 5-year lifetime is required to bring the operating cost down to $\$ 0.26 / \mathrm{M} \mathrm{SCF}$ where it could be cost competitive. 


\section{INTRODUCTION}

\section{OBJECTIVES}

The objective of this project was to determine the technical and economical feasibility of a novel $\mathrm{N}_{2}$ removal concept based on complexation of molecular $\mathrm{N}_{2}$ with organometallic complexing agents. During Phase II, we performed a complete design and construction of the bench-scale nitrogen absorption apparatus. High-pressure nitrogen absorption experiments were conducted to investigate the feasibility and to obtain scale-up parameters for designing a commercial system.

Throughout Phase I of this project, several organometallic chemicals had been identified that could react with $\mathrm{N}_{2}$, a highly inert molecule, reversibly and selectively. The molybdenum phosphine complex, $\left(\mathrm{PR}_{3}\right)_{2}(\mathrm{CO})_{3} \mathrm{Mo}$, was chosen as the complexing agent for investigation in Phase II. An ideal cost-effective technology would remove the minor component $\mathrm{N}_{2}$ from the inlet feed low-quality natural gas (LQNG) by contact with the complexing agent while delivering the purified product methane gas at essentially the feed pressure.

\section{BACKGROUND}

\section{Current Technology}

As previously discussed in the Phase I final report (SRI International, 1996), the three most widely used technologies for $\mathrm{N}_{2}$ rejections are cryogenic $\mathrm{N}_{2}$ rejection, pressure swing adsorption, and lean oil absorption. All these processes also remove methane, the major component, from the feed gas and therefore require large capital investments. The methane must be recovered, but because it is recovered from these processes at a pressure much lower than the feed pressure, recompression of the gas, a high-cost procedure is require to bring the treated gas to pipeline pressure for delivery. Even with methane recovery, these processes provide poor overall selectivity, resulting in the loss of more than $15 \%$ of the feed methane in the $\mathrm{N}_{2}$ rejection stream. Table 1 compares the production costs of current available technologies. 
Table 1

Comparison of Production Costs for Technologies Available for Nitrogen Removal from Methane

\begin{tabular}{|l|c|c|l|}
\hline \multicolumn{1}{|c|}{ Process } & $\begin{array}{c}\text { Gas Flowrate } \\
\text { (MM SCFD) }\end{array}$ & $\begin{array}{c}\text { Production Cost } \\
(\mathbf{\$} / \mathbf{M} \mathbf{S C F})\end{array}$ & \multicolumn{1}{|c|}{ Reference } \\
\hline Cryogenic & 2 & $\begin{array}{c}1.00 \\
0.20-0.33\end{array}$ & Changela et al., 1991 \\
\hline $\begin{array}{l}\text { Pressure swing } \\
\text { Adsorption }\end{array}$ & 75 & $1.50-1.60$ & $\begin{array}{l}\text { Echterhoff and } \\
\text { Pathak, 1991 }\end{array}$ \\
\hline Lean oil absorption & 1 & 3.00 & $\begin{array}{l}\text { Echterhoff and } \\
\text { Pathak, 1991 }\end{array}$ \\
\hline
\end{tabular}

\section{Proposed Technology}

In Phase I of this project, we screened complexing agents in terms of their binding capacity and reversibility. We established certain criteria for screening the nitrogen complexing agents. The desired properties for a successful complex were as follows:

- The complex must absorb/react with $\mathrm{N}_{2}$ at the feed gas conditions of high pressure and release $\mathrm{N}_{2}$ at lower pressures for regeneration.

- The complex must bind and release $\mathrm{N}_{2}$ sufficiently and rapidly.

- The complex should not bind with $\mathrm{CH}_{4}$ at partial pressures of 1000 psia.

- The complex must be thermally stable and retain its ability to bind and release $\mathrm{N}_{2}$ through pressure cycling.

- The complex must be stable in the presence of hydrocarbons, $\mathrm{CO}_{2}, \mathrm{H}_{2} \mathrm{~S}$, and $\mathrm{O}_{2}$.

Based on the above criteria, (bis)tricyclohexylphosphine molybdenum tricarbonyl was selected. The nitrogen-absorbing ability of the nonaqueous complex was measured in two batch gas absorption test apparatuses, one for low-pressure (atmospheric) and the other for highpressure (200-650 psia) (refer to Phase I final report).

This demonstration showed that the complex does not bind as readily with $\mathrm{N}_{2}$ at lower pressures as it does at higher pressures. Nitrogen absorption tests were also performed in the presence of methane. The results indicated that methane does not hinder the binding of the $\mathrm{N}_{2}$ with the complex (Phase I Final Report, pp. 26-40). These tests showed that the complex met the requirements of the design criteria for a successful complex. 
Nevertheless, synthesizing the complex in larger scale (7-10 L) was much more difficult than anticipated. With available funding and time constraints, our chemistry group was able to provide us with only two 7-L batches of molybdenum phosphine complex for high-pressure absorption experiments. The assembly, testing, and startup of the bench-scale apparatus also required more time and effort than expected. As a result, we did not have enough material or time to test the complex's sensitivity and stability in the presence of hydrocarbons, $\mathrm{CO}_{2}, \mathrm{H}_{2} \mathrm{~S}, \mathrm{O}_{2}$, and water and to conduct bench-scale tests to demonstrate the feasibility of the approach to nitrogen removal.

We decided to skip tests of sensitivity and stability and go directly to the demonstration because the indications during Phase I were that the phosphine complex was stable enough with respect to hydrocarbons and $\mathrm{CO}_{2}$. The complex would be protected from any sensitivity to oxygen, sulfide, and water by operating with pure dry gases and by conducting all manipulations in a dry box with an inert atmosphere. 


\section{RESULTS AND DISCUSSION}

\section{PROPOSED CONTINUOUS OPERATION OF BENCH-SCALE TEST APPARATUS}

Figure 1 shows the final constructed schematic of the bench-scale nitrogen absorption test apparatus. This system was constructed based on the following design assumptions:

- Scale down from a plant size capable of treating 1 MM SCFD at 1000 psia

- Inlet gas composition of $20 \% \mathrm{~N}_{2}$ and $80 \% \mathrm{CH}_{4}$

- Exit gas composition of $4 \% \mathrm{~N}_{2}$ and $96 \% \mathrm{CH}_{4}$

- Operating pressure and temperature of 1000 psia and $20^{\circ} \mathrm{C}$, respectively

- Inlet and exit gas flowrates based on no methane loss

- Phosphine complex solubility in toluene of $60 \mathrm{mM}$.

- Dissolved nitrogen concentration in feed toluene recycled to adsorption tower of $5 \mathrm{mM}$.

- Nitrogen-bound phosphine complex insoluble in toluene

- Henry’s constant of 2920 psi-liter/mol (International Critical Table, 1928)

- $50 \%$ nitrogen saturation of the toluene at exit conditions

- $50 \%$ utilization of the phosphine complex solution at exit conditions

- The calculated column cross sectional area and the diameter based on 50\% flooding point.

Appendix A discusses these assumptions in more detail.

The bench-scale apparatus is capable of processing $0.25 \mathrm{M} \mathrm{SCFD} \mathrm{(=} 5 \mathrm{~L}(\mathrm{STP}) / \mathrm{min})$ of gas at pressures of up to 1000 psia. The absorption column is 1-1/4 inch in diameter and 3.9 feet high and contains 1/4-inch stainless steel Raschig rings. Materials of construction used in the system and the filtration unit (such as pipes and fittings, O-rings, membrane filter, pumps and packing) were chosen based on the operating pressure and their compatibility with toluene and the organometallic complex. The liquid lines were 3/8-inch tubing made of 316 stainless steel, and the gas lines were 1/4-inch stainless steel (316) tubing. All valves and fittings were also made of 316 stainless steel. 


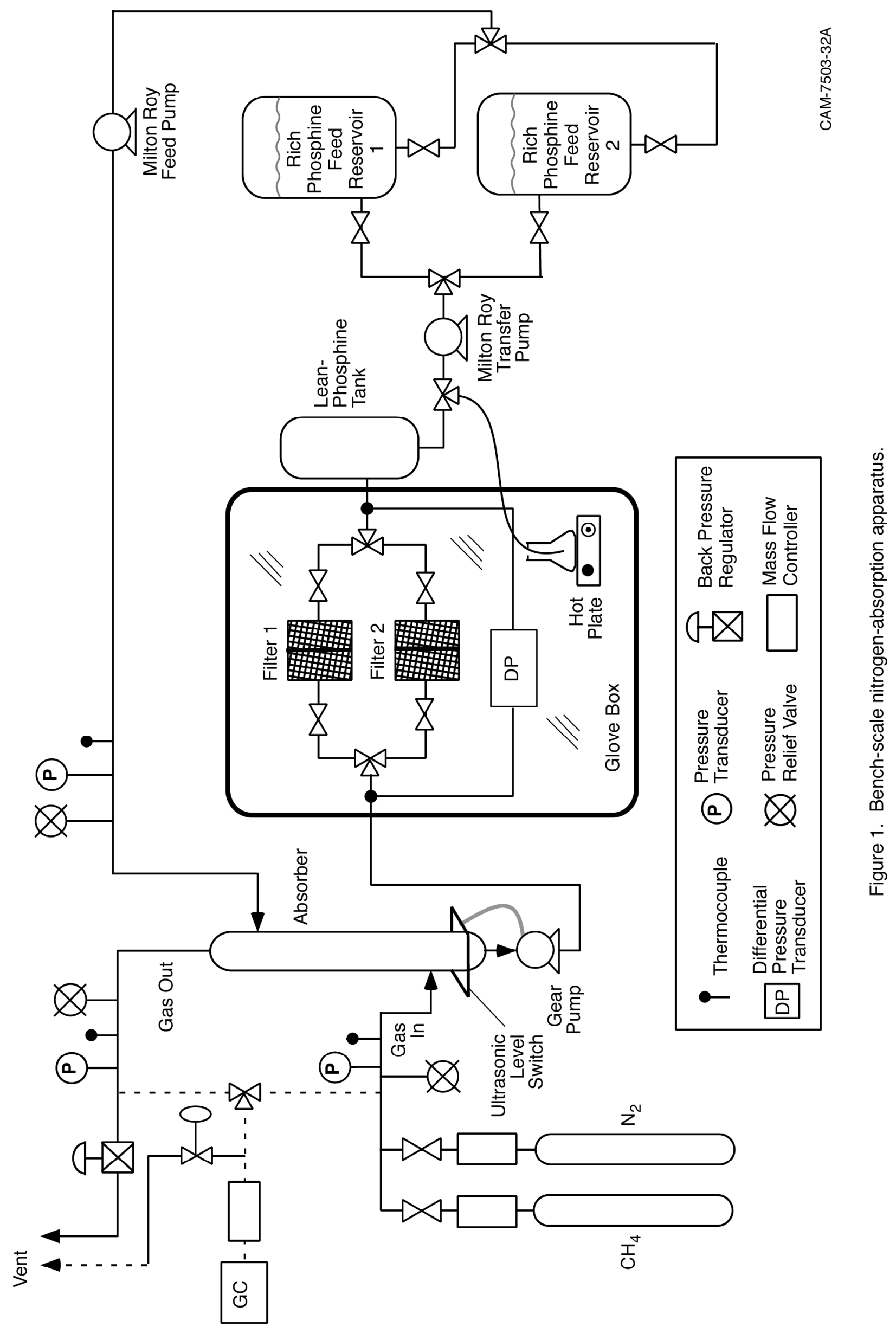


Before the start of each experiment, the system was flushed out thoroughly with pure methane and then pressurized to the desired operating pressure. Once at the desired pressure, methane and nitrogen were introduced into a mixing tee by mass flow controllers (Brooks Instruments, Model 5850E). The flowrates were set in a way to achieve an inlet gas composition of $20 \% \mathrm{~N}_{2} / 80 \% \mathrm{CH}_{4}$. The gas mixture entered the absorber from the bottom. The gas in the absorber contacted the liquid absorbent (either blank toluene or molybdenum phosphine complex) that was pumped from the feed reservoir using the Packed Plunger metering pump (Milton Roy, Model Number MBP101). Most of the treated gas was vented, but a sample stream was sent to a gas chromatograph (Hewlett-Packard, 5890) for composition analysis.

For the molybdenum phosphine complex solution experiments, the gas and the complex solution came in contact inside the absorber. Nitrogen was readily absorbed by the toluene solution and the phosphine complex. The nitrogen-bound complex formed a yellow precipitate. In addition, methane dissolved in the toluene. The regeneration scheme was designed to avoid methane loss by handling the bulk of the fluid and the nitrogen-bound complex separately.

The solution containing the nitrogen-bound complex was pumped through a filtration system via a metering drain pump (Packed Plunger metering pump, Milton Roy model MBP 101) located after the absorption column. Originally, a magnetic-drive gear pump (Flo-Line technology) was placed after the absorber to transfer the bound complex to the filtration system. However, the nitrogen-bound solids accumulated in the pump head, damaging the pump magnet and blocking the liquid flow. Therefore, we had to replace the gear pump with the Packed Plunger metering pump. The Milton Roy pump could provide slurry flowrate of 0.1-1.1 liters/min and could handle inlet and discharge pressures of 1000 psi. This pump is also capable of handling less than 5 psi differential pressure across the pump head, which is a requirement for our closed system. The material of construction for the O-rings and pump packing was Teflon. Packed Plunger metering pumps were used for feed, drain, and the transfer pump.

Once the complex reached the filtration system, the precipitate collected on the filter (membrane filter LS $47 \mathrm{~mm}$, Millipore), which is located inside an argon atmosphere dry glove box. The filtrate (lean-phosphine solution), which still contained the nitrogen and methane dissolved in the toluene, was sent to the lean-phosphine holding tank, and maintained under the system pressure so that no degassing occurred. As soon as the amount of precipitate had reached the first filter's loading capacity (as measured with a differential pressure gauge across the filter), the liquid flow was switched to the second filter. The second filter then continued to collect the solid $\mathrm{N}_{2}$-bound complex. 
During this time, the first filter was taken off-line, depressurized, and disassembled in an inert atmosphere. The solid $\mathrm{N}_{2}$-bound complex was washed off with dry toluene that had been prepared by distillation over sodium. A minimal amount of methane was released during depressurization because there was still some of the toluene solution in the pore spaces between the solid particles. The $\mathrm{N}_{2}$ was desorbed from the complex because of the original depressurization, but additional desorption was fostered by heating the solids in the toluene (to about $115^{\circ} \mathrm{F}$ ) with agitation. A color change of this toluene from dark brown containing yellow precipitates to a purple solution was an indication of a successful regeneration. The regenerated solution (purple) was repressurized and pumped along with the lean-phosphine solution to the second feed tank, ready to be pumped in for the next cycle.

When the system was operated, it was found that disassembling the filter and completing the complex regeneration procedure took about 30 minutes, which was longer than expected and longer than it took for the second filter to fill with solids. To deal with this timing mismatch, the process operation had to be performed in semi-batch fashion. In this method, once we had reached the loading capacity of the filter (as measured with the differential pressure gauge), gas and liquid flows were stopped temporarily. The regeneration procedure was conducted, and the regenerated complex and the lean-phosphine complex were pumped via the transfer pump to the feed reservoir. Once the entire regenerated complex had been transferred to the feed tank, the process was restarted, keeping all process parameters constant.

\section{HIGH PRESSURE BLANK TESTS WITH PURE TOLUENE}

We performed a series of high-pressure blank experiments (pure toluene used as absorbent liquid) on the bench-scale nitrogen-absorption apparatus. The system was initially pressurized with pure methane. Once the system reached the desired pressure, nitrogen was introduced such that the feed gas contained $20 \% \mathrm{~N}_{2}$ and $80 \% \mathrm{CH}_{4}$. Toluene, the absorbent liquid, was simultaneously pumped through the system. Initially, the feed gas flowrate was set at $0.219 \mathrm{~mol} / \mathrm{min}(\sim 0.25 \mathrm{M} \mathrm{SCFD}=4.9 \mathrm{SLPM})$, while the toluene circulation rate was set at approximately $700 \mathrm{~mL} / \mathrm{min}$. This resulted in a liquid-to-gas ratio (L/G) of approximately 0.14 . These liquid and gas flowrates were based on the design calculations for the bench-scale system. When the system was first tested, flooding occurred in the absorption column even though the design predicted that no flooding would occur. The flooding caused toluene to carry over into the gas lines and damaged the mass flow controllers. Therefore, we decided to decrease both the gas and liquid flowrates to $0.09 \mathrm{~mol} / \mathrm{min}$ (1.98 SLPM =0.1 M SCFD) and $280 \mathrm{~mL} / \mathrm{min}$, respectively, while keeping the $\mathrm{L} / \mathrm{G}$ constant to move farther away from the flooding point. 
Experiments with blank toluene were conducted at the lower flowrates to explore the behavior of the bench-scale system. The first tests were conducted at three pressures while keeping liquid and gas flows at constant rates (same L/G). We then conducted three experiments in which the $\mathrm{L} / \mathrm{G}$ ratio was changed by changing gas rates to test for mass transfer rate effects. Finally, two experiments were conducted in which the L/G ratio was changed by changing the liquid rate. All these blank experiments were conducted in triplicates and the results were reproducible to within $5 \%$.

Figure 2 illustrates the results for the first tests and shows the absorption profile of nitrogen in toluene at pressures of 200, 500, and $750 \mathrm{psig}$ at an L/G of approximately 0.14 . For all three runs, the inlet gas flowrate was set at $0.09 \mathrm{~mol} / \mathrm{min}$ (1.98 SLPM $=0.1 \mathrm{M} \mathrm{SCFD}$ ), while the toluene flowrate was approximately $280 \mathrm{~mL} / \mathrm{min}$. As absorption began, the $\mathrm{N}_{2}$ outlet concentration was initially low, but it gradually increased over time, reaching the inlet concentration indicating that the toluene was fully saturated with nitrogen.

This result demonstrated that, at the flowrates involved, system behavior was determined by equilibrium relationships rather than by mass transfer. As expected the total nitrogen absorbed increased with an increase in pressure. The breakthrough times were approximately 1000, 1400, and $2000 \mathrm{~min}$ for 200,500 , and 750 psig, respectively.

For all three pressures $\left(200,500\right.$, and 750 psig), we calculated the amount of $\mathrm{N}_{2}$ absorbed (area above the curve but below 20\%) by liquid. For instance, for the 750-psig data, the following third-degree polynomial was curve fitted through the data points:

$$
C_{0}=-0.44591+0.0347(t)-2.68 \times 10^{-5}(t)^{2}+7.33 \times 10^{-9}(t)^{3}
$$

The area under the curve was then calculated by integrating Equation (1) from 0 to 2000 min (20\% saturation time). To calculate the percent nitrogen absorbed, the calculated amount from the integration was then subtracted from the total area under $20 \%$ as shown in Equations (2) and (3):

$$
\begin{aligned}
& \text { total area under } 20 \% \mathrm{~N}_{2}=20 \text { (total } \mathrm{N}_{2} \text { concentration) } \times 2000(\mathrm{~min})=40000 \\
& \qquad \% \mathrm{~N}_{2} \text { Absorbed }=40000-\int_{0}^{2000} \mathrm{C}_{0} \mathrm{dt}
\end{aligned}
$$

The percent $\mathrm{N}_{2}$ absorbed was multiplied by the molar flowrates of the feed gas to calculate the moles of $\mathrm{N}_{2}$ absorbed. The estimated nitrogen concentrations in the toluene at 200, 500, and $750 \mathrm{psig}$ (nitrogen partial pressures of 40,100 , and $150 \mathrm{psig}$ ) were $0.4 \mathrm{M}, 1.05 \mathrm{M}$, and $1.6 \mathrm{M}$, respectively. As expected, nitrogen absorption increased as a function of nitrogen partial pressure. 


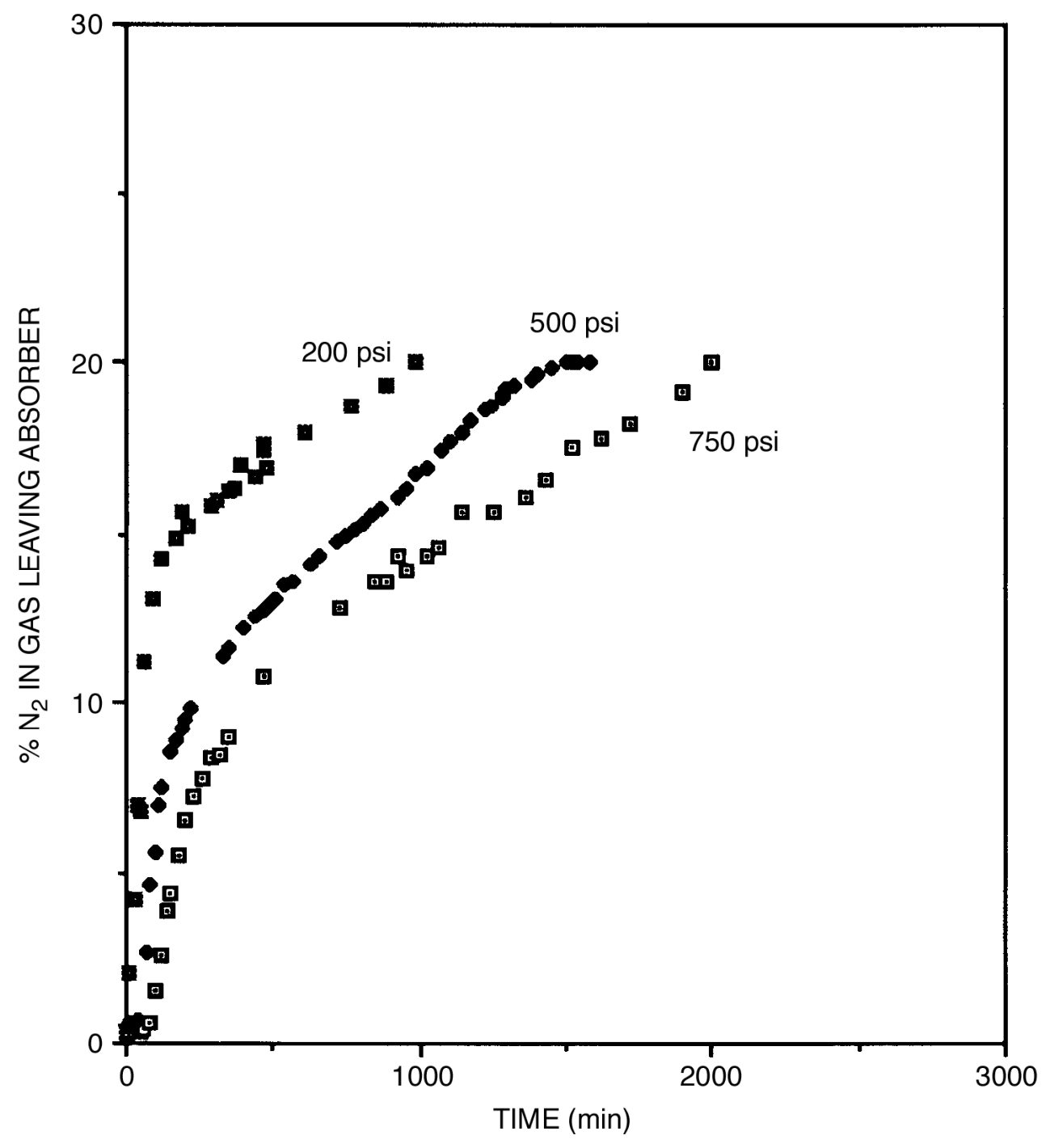

CM-7503-35

Figure 2. Nitrogen-toluene absorption profile at three pressures $(L / G=0.14)$. 
Figure 3 shows the relationship between $\mathrm{N}_{2}$ 's partial pressure in the gas phase and the calculated molar concentration of $\mathrm{N}_{2}$ in toluene. The data points are fitted by a straight line, which indicates that the amount adsorbed is a linear function of the nitrogen partial pressure. This observation suggests that the nitrogen absorption in our system is dominated by equilibrium phenomena rather than by mass transfer. Figure 3 cannot be used, however, to estimate the Henry's law for the system because, although the fluid in the absorption column may be in equilibrium with the gas leaving the absorber, the bulk of the fluid in the system is in the feed tank, where it has not been exposed to the gas for some time.

Figure 4 shows the effect of three different L/G for a same system pressure of 200 psig. For the L/G of 0.14 and 0.28 , the liquid flowrate was kept constant and the gas flowrate was varied. As expected, the toluene saturation required longer time at the lower gas flowrates for a fixed liquid flowrate because there was less nitrogen entering the system per unit time at the lower flowrates.

Figure 5 illustrates the effect of different liquid flowrates and constant gas flowrates at two L/G. We see that no substantial change was observed on the breakthrough time. Since with constant gas flowrate, we were introducing the same moles of nitrogen per unit time, this result would be anticipated if mass transport rates were so rapid as to be unimportant. This in fact was another indication that this system was dominated by equilibrium.

\section{HIGH PRESSURE EXPERIMENTS WITH MO-PHOSPHINE COMPLEX}

High pressure nitrogen absorption experiments were conducted to test the feasibility using the molybdenum phosphine complex identified in Phase I in a continuous flow apparatus.

\section{Preparation of Phosphine Complex for Bench Scale Experiments}

Two 7-L batches of the molybdenum phosphine complex were synthesized. Two obvious synthesis routes were available_ one starting from commercially available molybdenum tricarbonyl complex, and the other starting with more fundamental reagents to produce the molybdenum tricarbonyl complex first. The commercially available molybdenum tricarbonyl complex is expensive, but the route using it was chosen because it required less labor cost. The chosen route reacts cycloheptatriene molybdenum tricarbonyl with tricyclohexyl phosphine in an ether solution to produce (bis)tricyclohexylphosphine molybdenum tricarbonyl, which is the unbound form of the nitrogen complexing agent. 


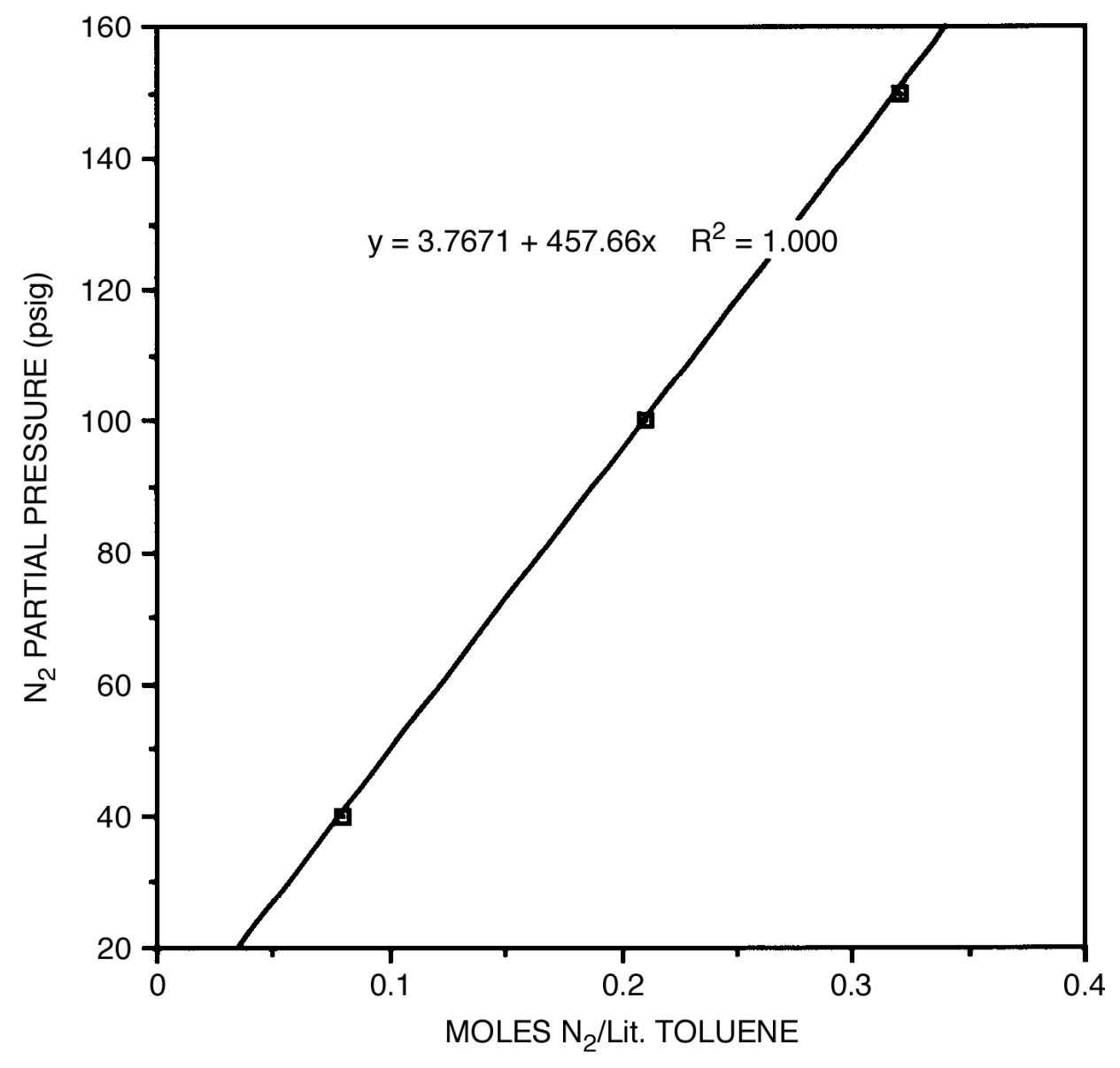

CM-7503-36

Figure 3. Equilibrium line for $\mathrm{N}_{2}$ partial pressure versus moles of $\mathrm{N}_{2}$ absorbed by toluene experimentally. 


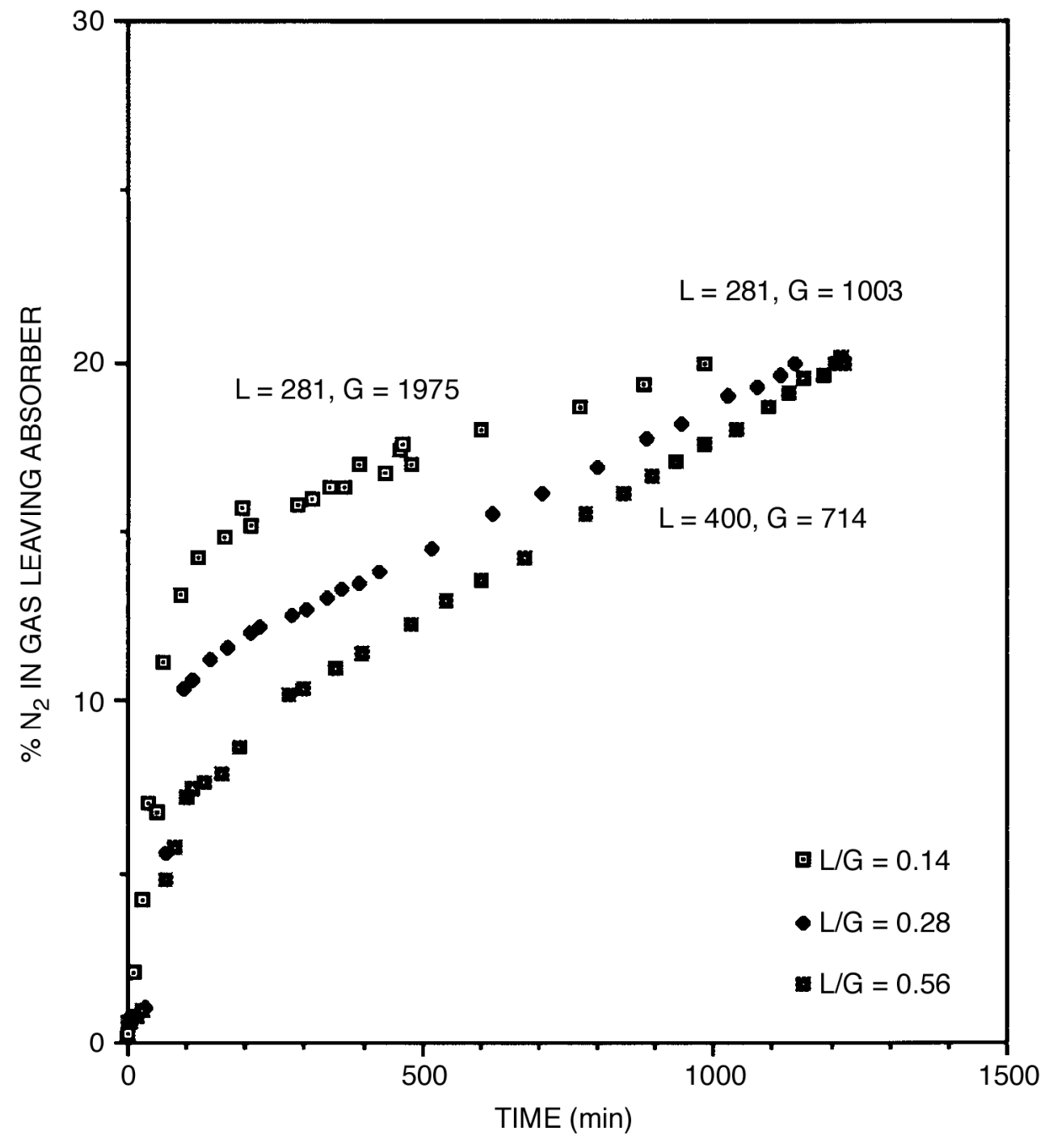

CM-7503-37

Figure 4. Nitrogen-toluene absorption profile at 200 psi for different $L / G$ ratios. 


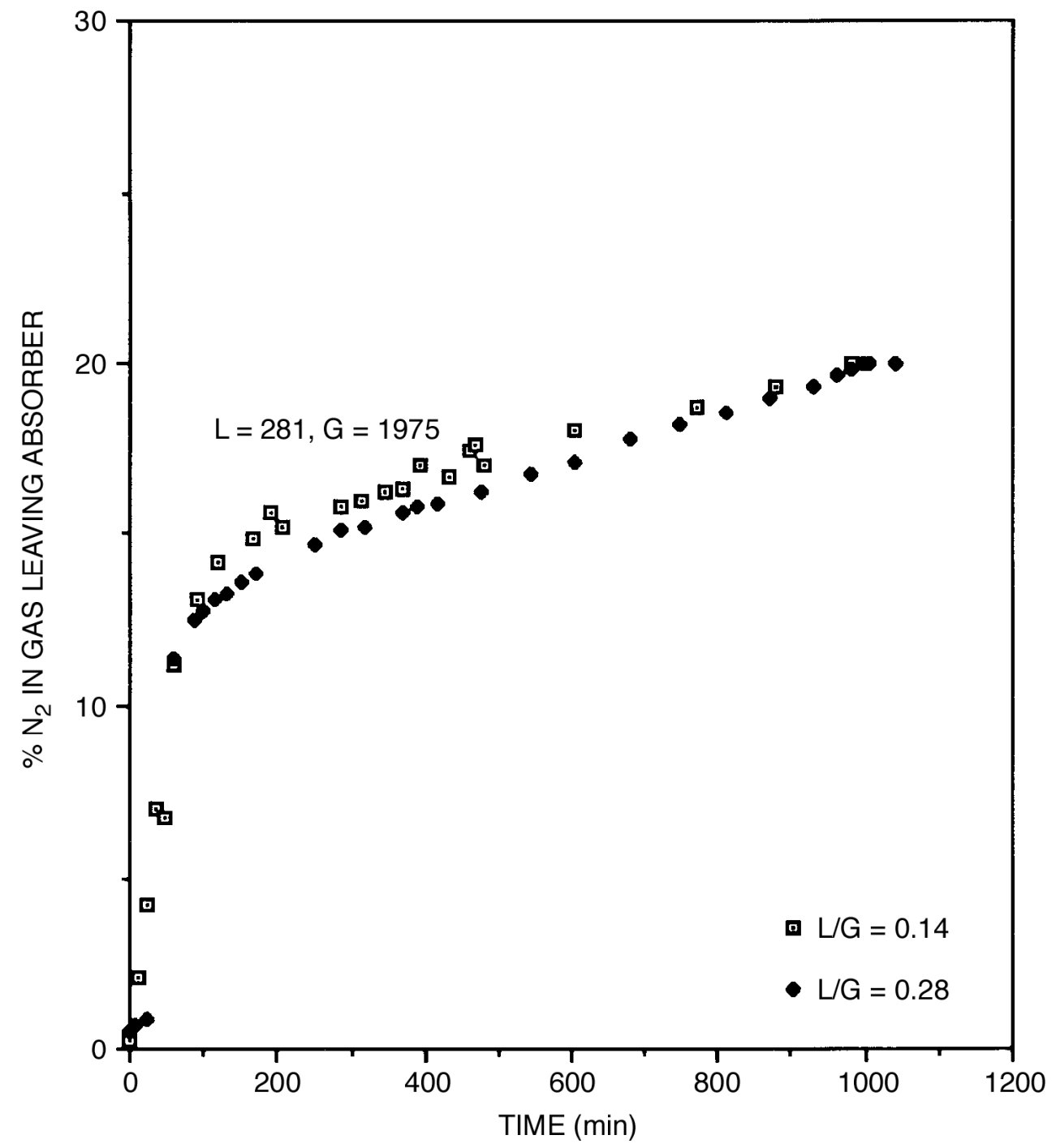

CM-7503-38

Figure 5. Nitrogen-toluene absorption profile at $200 \mathrm{psi}$ and different $L / G$ (same gas flowrate). 


\section{$\mathrm{C}_{7} \mathrm{H}_{8}$}

\section{Ether, Room temperature \\ $\left[\mathrm{Mo}(\mathrm{CO})_{3}\left(\mathrm{C}_{7} \mathrm{H}_{8}\right)\right]+2 \mathrm{PCy}_{3}-\cdots-\cdots$}

$\begin{array}{llll}\text { Amount: } & 171.4 \mathrm{~g} & 354.3 \mathrm{~g} \quad 2.0 \mathrm{~L} & \\ \text { MW: } & 272 \mathrm{~g} / \mathrm{mol} & 280.4 \mathrm{~g} / \mathrm{mol} & 740.8 \mathrm{~g} / \mathrm{mol} \\ \text { mol: } & 0.630 \mathrm{~mol} & 1.26 \mathrm{~mol} & 0.315 \mathrm{~mol}\end{array}$

Expected yield $=70 \%$.

The reaction was performed in two vessels, each containing half of the total reagent/solvent amounts. The two batches each contained $86 \mathrm{~g}$ of the molybdenum reagent, one liter of solvent, and $178 \mathrm{~g}$ of the phosphine. Glassware for this procedure was dried in an oven at $110^{\circ} \mathrm{C}$, cooled under vacuum, and then filled with argon to eliminate water and oxygen. Argon, being heavier than air, allows some manipulation of the glassware to add solvents and reagents without significant exposure of the contents to oxygen or water in the laboratory air.

The solvent was degassed with argon prior to adding the molybdenum reagent. The molybdenum reagent is temperature sensitive and was stored in a refrigerator. Prior to starting the reaction it was removed from the refrigerator and allowed to warm up to room temperature under argon. The reaction vessels were 2-L Schlenk flasks containing large football-shaped stirring bars. The molybdenum starting material was added to the vessel first and placed under vacuum for 30 minutes. The vacuum was replaced with argon, the degassed ether was added, and the solid dissolved completely by stirring. The phosphine was added as a solid in one portion. Stirring the mixture was initially difficult but became adequate after the addition of more ether $(350 \mathrm{~mL}$ to each flask. The septa stoppers on the flask were replaced with glass stoppers and the reaction was left stirring under argon overnight. The purple product precipitates, along with an orange intermediate, from an orange solution during the reaction.

The crude solid product suspended in the ether solvent was transferred from the 2-L Schlenk flasks under argon pressure through a cannula into a 2-liter fritted funnel. The solid was collected on the frit under an argon atmosphere and the filtrate was collected in a 5-liter Schlenk flask. Both batches were filtered into the same 5-L receiving flask. The solid in the filter was washed with an ether:heptane (1:1) mixture prepared by mixing anhydrous ether with reagent grade heptane and degassing by sparging with argon. The solid remaining in the fritted funnel was dried in vacuo to a constant weight. 
The dried solid was dissolved in a minimum amount of toluene that had been dried by distillation over sodium. The toluene was added to the fritted funnel and the resultant slurry was transferred though the cannula to 5-L flasks under argon. The solution (containing some solid impurities) was then transferred into a cleaned and dried fritted funnel and filtered into two 5-L flasks. The total volume was $6 \mathrm{~L}$ at a concentration of about $0.045-0.06 \mathrm{M}$.

\section{Determining the Correct Pore Size of the Membrane Filter}

The first task was to perform a test to obtain an approximate measurement for the particulate size of the precipitated $\mathrm{N}_{2}$-bound phosphine complex. During the final stage of the complex synthesis, the phosphine solution was passed through a $16-\mu \mathrm{m}$ fritted filter. Therefore, if the complex solution contained any fine suspended molybdenum solids, these solids were smaller than $16 \mu \mathrm{m}$. After an absorption experiment, there could be two different types of solids in the solution: the nitrogen bound solids, which are yellow, and the unbound molybdenum solids, which were deep purple.

Before the start of these experiments, all contamination from the bench-scale nitrogen absorption apparatus was removed by flushing the system thoroughly with toluene. Pure methane gas (WESCO Corp., 99.999\% Research Grade) was then pumped into the system to remove any air, which might have entered the apparatus previously. This was done by pressurizing the entire system to 400 psig with pure methane and venting it to atmospheric pressure at least three times. Then the system was pressure tested with methane to eliminate any minor leaks from the valves and the fittings. Once we ensured this practically leak-free atmosphere, the first batch $(7.5 \mathrm{~L})$ of $43 \mathrm{mM}( \pm 2)$ phosphine complex was pumped into the apparatus under the pure argon atmosphere (WESCO Corp., 99.999\% Research Grade) in such way to prevent air from entering the system.

Initially, a 5- $\mu \mathrm{m}$ membrane filter (membrane filter LS $47 \mathrm{~mm}$, Millipore) was placed inside the filter housing in the regeneration system. The liquid-to-gas ratio $(\mathrm{L} / \mathrm{G})$ for each experiment was set at 0.6 with the liquid and gas flowrates at $240 \mathrm{~mL} / \mathrm{min}$ and $0.018 \mathrm{~mol} / \mathrm{min}(0.4 \mathrm{SLPM}=$ $0.02 \mathrm{M}$ SCFD), respectively. These flows are different from the flows used in the pure toluene experiments and different from the design flows because the phosphine complex (43 $\mathrm{mM})$ did not have the concentration assumed in the design calculations $(60 \mathrm{mM})$. Using the design equations for the column as a basis, the liquid and gas flowrates and the $\mathrm{L} / \mathrm{G}$ ratio had to be reduced to produce an exit gas with a composition of less than $4 \% \mathrm{~N}_{2}$ during continuous operation of the system. The drain pump flowrate $(260 \mathrm{~mL} / \mathrm{min})$ was set slightly higher than the feed pump flowrate to avoid flooding the column.

These filters provided too much blockage. It took approximately 3 minutes for enough solids to collect on the filters to almost completely block liquid flow and put the differential 
pressure across the filtration outside its limit (22 psi). This blockage occurred so rapidly that it prevented gas composition measurements. Upon depressurization and disassembly of the filtration unit, we noticed that mostly purple solids rather than the nitrogen bound (yellow) were being collected on the filter. Either there was an abundance of unbound as opposed to the bound precipitates in the system, or the $\mathrm{N}_{2}$-bound precipitates were too small to be collected on the 5 - $\mu \mathrm{m}$ filter. The former is probably true because little nitrogen would have been absorbed in the short run, but the latter could introduce a major problem as far as regeneration. If the particulate size for the nitrogen bound complex is smaller than that of the unbound, or the unbound phosphine complex concentration in the toluene cannot be reduced to the point where it is soluble, the filtration method will not be sufficient to regenerate the complex in its entirety.

We decided to test larger pore size membrane filters to identify a filter medium that would allow longer run times, which might in turn generate sufficient bound complex to be captured. The experiment would help determine the particle size of the material being captured. We performed an identical set of experiments using 60- and 80- $\mu \mathrm{m}$ membrane filters (membrane filter LS $47 \mathrm{~mm}$, Millipore). After approximately 20 minutes of operation at 200 psig with each filter, we did not observe any change on the differential pressure across the filtration unit. Hence, the filter housing was isolated, depressurized, and taken off-line for disassembly. We could barely trace solids or precipitates on the membrane filter. Therefore, switching to a filter with pore size somewhere between 5 and $60 \mu \mathrm{m}$ was a reasonable adjustment.

We tested a 20- $\mu$ m membrane filter (membrane filter LS $47 \mathrm{~mm}$, Millipore). After approximately 20 minutes of operation, the differential pressure had exceeded the limit (22 psi). Upon disassembling the filtration unit, we observed a collection of mostly purple and some yellow particulate that had formed on the filter. Based on the gas concentration measurements, we expected $10 \%$ of the total captured solids to be the yellow $\left(\mathrm{N}_{2}\right.$-bound) solids. However, it appeared that approximately $1 \%$ of the solids were yellow and the rest were purple molybdenum solids. Nevertheless, we decided that the 20 - $\mu$ m filter was sufficient for collecting some of the nitrogen-bound complex. Therefore, the decision was made to proceed to a series of high-pressure absorption tests using $20-\mu \mathrm{m}$ membrane filters.

At this point, the complex solution in the feed tank was dark brown containing yellow and green precipitate. The entire complex solution and the entrained particles were pumped out of the system and heated over the hot plate inside the argon atmosphere dry glove box to determine if it could be regenerated. Unfortunately, the complex did not go back to its original purple color (unbound form), and the yellow precipitates remained suspended even after heating. There are at least three known causes of a yellow precipitate in this system, in addition to the reaction with nitrogen complex bound to water. Oxidation forms a yellow precipitate, and a bimolecular 
decomposition reaction forms a yellow precipitate. The bimolecular decomposition is an intrinsic reaction that is not caused by exposure to chemicals. Phase I experiments suggested, however, that the bimolecular decomposition requires a period of weeks to have a significant effect.

Because the yellow solids could not be eliminated by a regeneration procedure, we concluded that this batch of complex was degraded by one or more of the above mechanisms and had lost its ability for nitrogen absorption. We assumed that the degradation had occurred because of the excess manipulations involved in shaking down the apparatus. Therefore, we decided to discard the used up batch and flush the system to have it ready for a fresh batch of the complex.

During the clean-up of the system in preparation for another series of runs, which is discussed below, we observed an accumulation of yellow solids inside the absorber and before the drain pump. The Raschig rings inside the absorption column were collecting these solids and keeping them from being removed on the filter. This observation suggests that most of the $\mathrm{N}_{2^{-}}$ bound solids never reached the filtration unit and were never regenerated. This accumulation effect in the column adversely affects the performance of the bench-scale unit and its ability to operate continuously, with the complex being shuttled between the bound and unbound state.

\section{Apparatus Clean-Up}

Because of the nature of the complex and its sensitivity, flushing the apparatus in preparation for another set of experiments had to be performed thoroughly and was quite involved. We first flushed the entire system with $0.1 \mathrm{M}$ potassium hydroxide in ethanol. This was followed by $20 \%$ acetic acid/ $80 \%$ water wash. Next, enough water was pumped into the system to wash out all the acid and base and to bring the system $\mathrm{pH}$ to neutral. Once the system's $\mathrm{pH}$ was approximately at 7, an acetone wash was performed to dehydrate the system. Over $60 \mathrm{~L}$ of industrial grade acetone was pumped through the apparatus. This was followed by a wash with hot toluene that had been dried by distillation over sodium to displace the acetone from the system. Finally, pure methane gas (WESCO, $99.999 \%$ research grade) was pumped into the system.

\section{Absorption Experiments}

The next batch of the complex was synthesized and pumped into the system after the thorough flushing of the apparatus. Five experiments were performed using this complex over a period of 4 weeks. The liquid-to-gas ratio ( $/ \mathrm{G})$ for each experiment was set at 0.6 with liquid flow rate of $240 \mathrm{~mL} / \mathrm{min}$ and feed gas flow rate of $0.018 \mathrm{~mol} / \mathrm{min}(0.4 \mathrm{SLPM}=0.02 \mathrm{M} \mathrm{SCFD})$. These are the same flow rates used in the experiments conducted to choose the filter pore size. The data from the molybdenum phosphine absorption experiments are given in Appendix B. 
The feed gas for all five experiments contained $80 \% \mathrm{CH}_{4} / 20 \% \mathrm{~N}_{2}$. The first two experiments were conducted at pressure of approximately $200 \mathrm{psig}$ (one day and one week after the complex had been synthesized). The system pressure for the next two runs was set at approximately 400 psig (completed 3 weeks after the complex had been synthesized). The final run was performed at 200 psig, four weeks after the completion of the synthesis and after conducting a vigorous regeneration method (explained later in this report). Note that for every experiment, the same batch of the complex was used as the absorbing liquid.

For each experiment, the system was initially pressurized using pure methane, a procedure identical to that of the blank tests. Once at the desired pressure, the flow of methane containing nitrogen gas was begun and the liquid flow was started using the feed pump. The feed gas entered the column from the bottom where it came into contact with the molybdenum phosphine complex in countercurrent flow. After leaving the column, the complex solution was pumped via the drain pump through the filtration system in the dry glove box and finally into the feed reservoir (refer to Figure 1). The flowrate of the drain pump was set slightly higher than that of the feed pump to ensure no flooding in the column. The outlet gas was sent to the vent, and once every 10 minutes a bleed stream of this gas was sent to a gas chromatograph for composition analysis.

Figure 6 illustrates the absorption profile for $\mathrm{N}_{2}$ on molybdenum phosphine complex at pressures of 200 and $400 \mathrm{psig}$. The absorption times for the outlet gas to reach $4 \%$ were 250 and $180 \mathrm{~min}$ for the first and second experiments at $200 \mathrm{psig}$, respectively. The time difference between these two identical experiments indicates that the nitrogen absorption capacity of the system had decreased. These results clearly show that the bound complex was not completely regenerated, or bound complex was accumulating in the system at some point other than the filter, or the complex had lost capacity to absorb nitrogen because of degradation. One potential accumulation point in the system is the absorption packing.

The two 400-psig experiments were conducted to determine whether the loss of absorption capacity reflected a change in the activity of the complex that reduced its ability to absorb nitrogen at low pressures or whether it represented a total loss of activity. The two absorption breakthrough curves follow almost identical paths. This indicates the reproducibility of our technique for the high pressure nitrogen absorption experiments using the phosphine complex. Nevertheless, because of the rapid breakthrough times, we assume that the failure to absorb nitrogen is not related to nitrogen pressure but to the fact that the complex had degraded and had lost some if not all its capacity to absorb nitrogen.

At the start of the first experiment, a 20- $\mu$ m membrane filter (membrane filter LS $147 \mathrm{~mm}$, Millipore) was placed inside the filtration housing. After approximately 20 minutes of operation, 


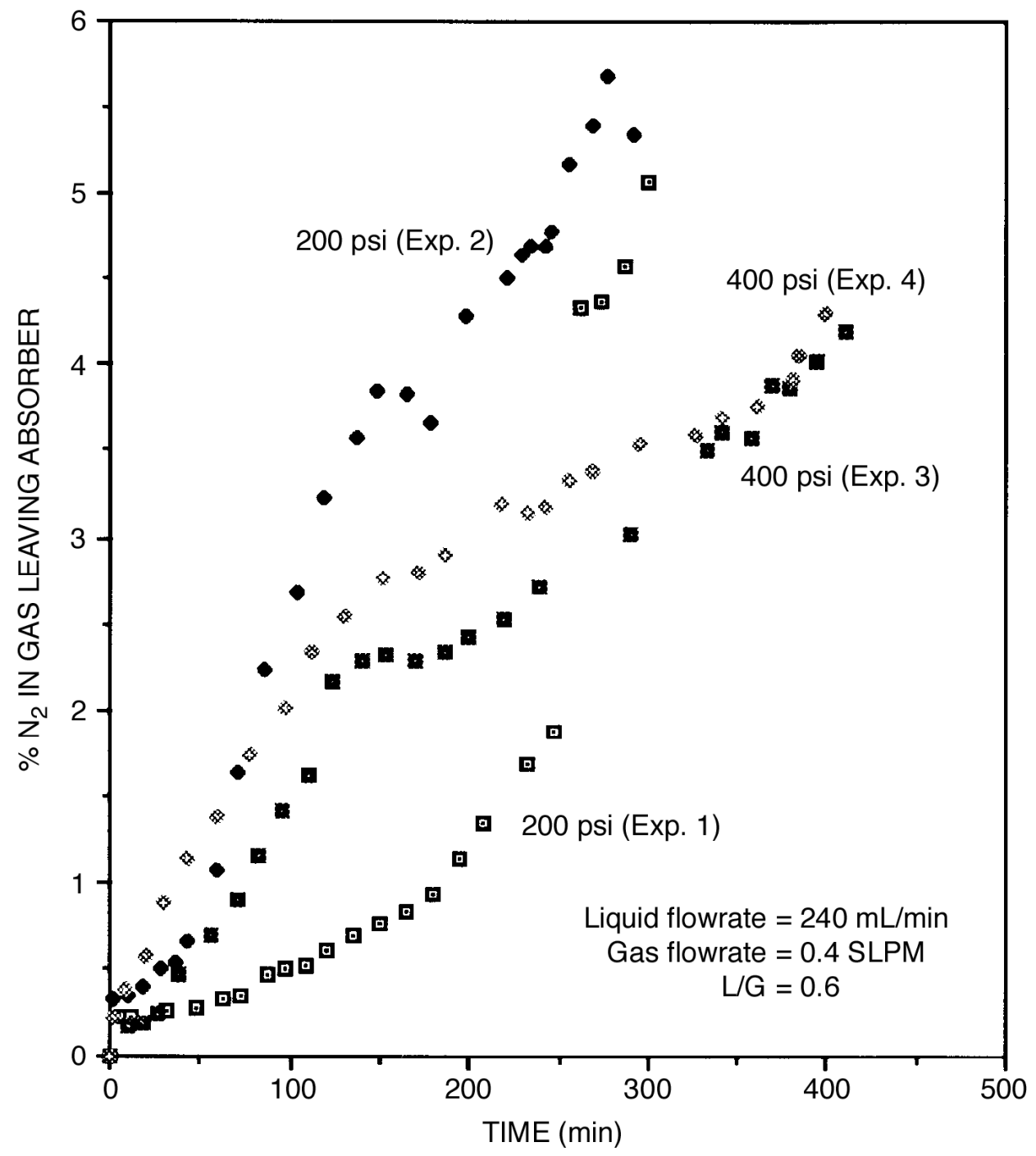

CM-7503-39

Figure 6. Nitrogen absorption profile on mo-phosphine complex at two pressures. 
the recorded pressure drop across the filter was excessively high (22 psi). Therefore, the filter housing was isolated, depressurized, and taken off-line for disassembly. Once the housing was disassembled, it was observed that almost no yellow precipitate had collected on the filter and that only a thin layer of purple precipitates was present on the membrane filter. This may have indicated that the particle size of the bound complex is smaller than that of the unbound form or that as in previous experiments the bound complex was collecting in the absorption column, either of which makes a successful complex regeneration procedure based on filtration difficult. At the end of each experiment, the system was depressurized to almost atmospheric pressure and flushed with methane in an attempt to regenerate the bound complex that might be held up in the absorber and not collected on the filter. However, this attempt did not seem to adequately regenerate the solution as indicated by the data in Figure 6.

Table 2 compares the theoretical solubility data for blank toluene (International Critical Table, 1928), the solubility data for the Mo-phosphine complex (from Phase I of this project), and experimental values that further support this finding. The $\mathrm{N}_{2}$ absorbed in the experiment was calculated as the area above the breakthrough curve. The calculation is explained earlier in this report.

\section{Table 2}

\section{Comparison of Theoretical and Experimental Data}

\begin{tabular}{|c|c|c|c|c|}
\hline Expt. \# & $\begin{array}{c}\text { Pressure } \\
\text { (psig) }\end{array}$ & $\begin{array}{c}\mathrm{N}_{2} \text { Absorbed } \\
\text { Based on Blank } \\
\text { Toluene Solubility } \\
\text { (mol) }\end{array}$ & $\begin{array}{c}\text { N2 Absorbed Based on } \\
\text { Complex + Toluene } \\
\text { Solubility * } \\
\text { (mol) }\end{array}$ & $\begin{array}{c}\mathrm{N}_{2} \text { Absorbed Based on } \\
\text { Experimental Data (area } \\
\text { above the curve) } \\
\text { (mol) }\end{array}$ \\
\hline 1 & 200 & 0.06 & 0.16 & 0.15 \\
\hline 2 & 200 & 0.05 & 0.14 & 0.06 \\
\hline 3 & 400 & 0.09 & 0.19 & 0.12 \\
\hline 4 & 400 & 0.07 & 0.14 & 0.09 \\
\hline
\end{tabular}

${ }^{*}$ The solubility was extrapolated from the experimental data obtained from Phase I of this project [Final Report, Phase I, page 40, Figure 16].

For the first experiment (200 psig), the amount of $\mathrm{N}_{2}$ absorbed is almost the same for the theoretical case (based on Phase I, $0.16 \mathrm{~mol}$ ) and the experimental data (approximately $0.15 \mathrm{~mol}$ ). The similarity between the experimental and theoretical data is believed to reflect the fact that the complex was never used before and it had bound readily to nitrogen. The difference between the theoretical and experimental data for the later experiments indicates that the system was not completely regenerated. As a matter of fact, the experimental data follow the blank toluene 
solubility data [International Critical Table, 1928] much closer, which suggests that, in the last experiments in the series, the toluene and not the complex is absorbing the nitrogen gas.

During the second experiment's regeneration procedure, we observed a noticeable change in the color of the phosphine complex. From the original purple, the complex changed to a dark brown containing yellow precipitates. This could indicate that regeneration was unsuccessful or that the degradation of the complex had already taken place even when it was stored under methane at high pressure (200 psig).

For the two 400-psig experiments, the times for the outlet gas to reach $4 \%$ were 390 and $380 \mathrm{~min}$, respectively. As expected, the absorption time had increased as a function of pressure. However, the experimental values for moles of nitrogen absorbed did not come close to the expected theoretical values (Table 2). This was taken as another indication that the complex had lost its capacity to absorb nitrogen and that any absorption observed was due to the toluene solvent present in the system.

Figure 7 compares the $\mathrm{N}_{2}$ absorption profile of blank toluene and the molybdenum phosphine complex (43 mM). This figure was constructed to test the hypothesis that, in the later runs, the toluene was the only agent responsible for nitrogen absorption. All three experiments were performed at the same L/G (approximately 0.6) and system pressure of $200 \mathrm{psig}$. However, the gas flowrate for the blank toluene run was 0.7 SLPM as opposed to 0.4 SLPM for the complex experiments. We can see from the figure that it took the blank experiment about 55 minutes to reach $4 \% \mathrm{~N}_{2}$ concentration in the exit gas. As previously explained, the absorption profile depends only on the amount of nitrogen passed through the system. Therefore, if we use a linear extrapolation to predict the absorption time for a blank toluene at a flowrate of 0.4 SLPM, we calculate it would have taken approximately 100 minutes to reach a $4 \%$ nitrogen concentration in the exit gas if the toluene were the only absorbent present. Fresh 43-mM phosphine complex (Exp. 1) extended the run time by a factor of three. The used phosphine complex (Exp. 2) did not extend the run time significantly.

Therefore, it appeared that the complex was not regenerated sufficiently following the first experiment. The first absorption cycle was reasonable, whereas later cycles were not.

\section{New Regeneration Procedure}

After the fourth experiment, we tested a new method of regenerating the Mo-phosphine complex solution. All the complex solution from the previous absorption experiments was pumped out of the system inside the dry glove box under the argon atmosphere in a manner that did not expose it to air or water. Any solids retained by the absorption packing or other parts of the system 


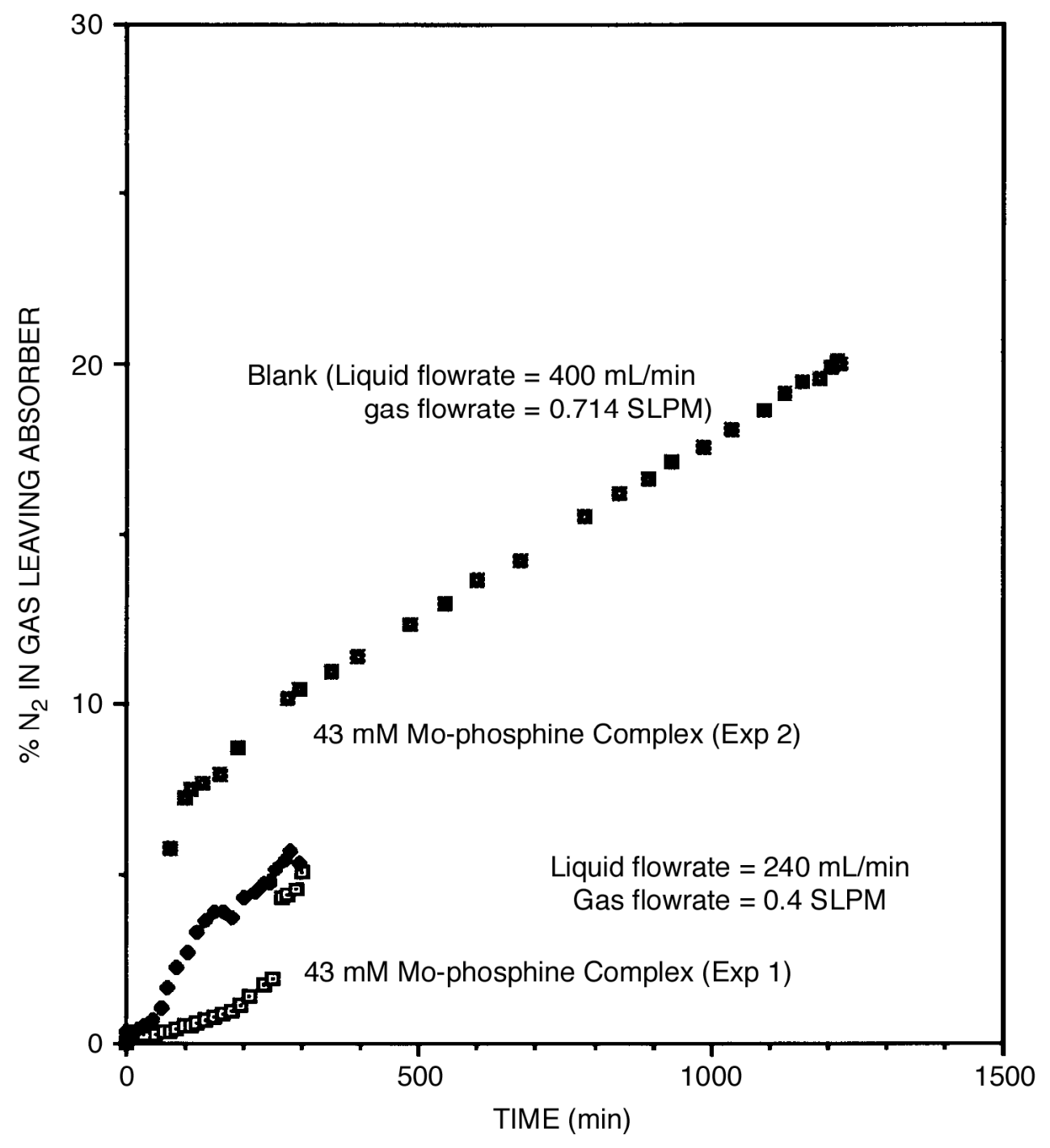

CM-7503-40

Figure 7. Complex versus blank at $200 \mathrm{psi}$ and $\mathrm{L} / \mathrm{G}=0.6$. 
were not removed by this procedure. The brown solution containing yellow precipitate that was collected was heated to temperature as high as $150^{\circ} \mathrm{F}$, which was well above the temperature required to achieve regeneration $\left(115^{\circ} \mathrm{F}\right)$. Unfortunately, the complex never went back to its original purple, the unbound form, but kept all its yellow solids, indicating that complete regeneration did not occur. The yellow solids must represent one or more of the degraded forms of the complex. However, because color change is not a precise method for identifying the extent of regeneration when degradation products are present, we performed another nitrogen absorption experiment at 200 psig to determine if the new regeneration procedure had restored some absorption activity.

Figure 8 illustrates the comparison between the three experiments performed at $200 \mathrm{psig}$ using the same batch of complex solution. The process parameters such as gas flowrate, liquid flowrates, and temperature were identical for these experiments. The third experiment was performed four weeks after complex synthesis and immediately after performing the new regeneration method (depressurization and heating the entire complex). This figure shows that the absorption time required for the outlet gas to reach $4 \% \mathrm{~N}_{2}$ concentration decreased from 250 to 180 and finally to 90 minutes for the first, second, and third experiments, respectively. It is clear that the more vigorous regeneration did not restore performance. The first absorption cycle represented reasonable performance, whereas later cycles did not.

There are at least five interpretations of the data:

(1) The phosphine complex is intrinsically unstable and decays with time. Under this interpretation, the useful complex lifetime may be somewhere between 3 and 5 weeks.

(2) The apparatus and the handling procedures did not completely eliminate exposure to air or water, which in turn caused degradation.

(3) The Rashig rings packing inside the absorber provided blockage for the nitrogen-bound solids, preventing some of the complex from reaching the filtration unit to be regenerated.

(4) The molybdenum solids ( $>12 \mu \mathrm{m}$ ) were larger than the $\mathrm{N}_{2}$ bound precipitates, which introduced difficulty for collecting the nitrogen-bound complex during the regeneration procedure. Most of the $\mathrm{N}_{2}$ bound precipitate was passed through the filtration system without being regenerated.

An unanswered question is whether the complex is more stable with respect to degradation when it is in the bound or the unbound form. 


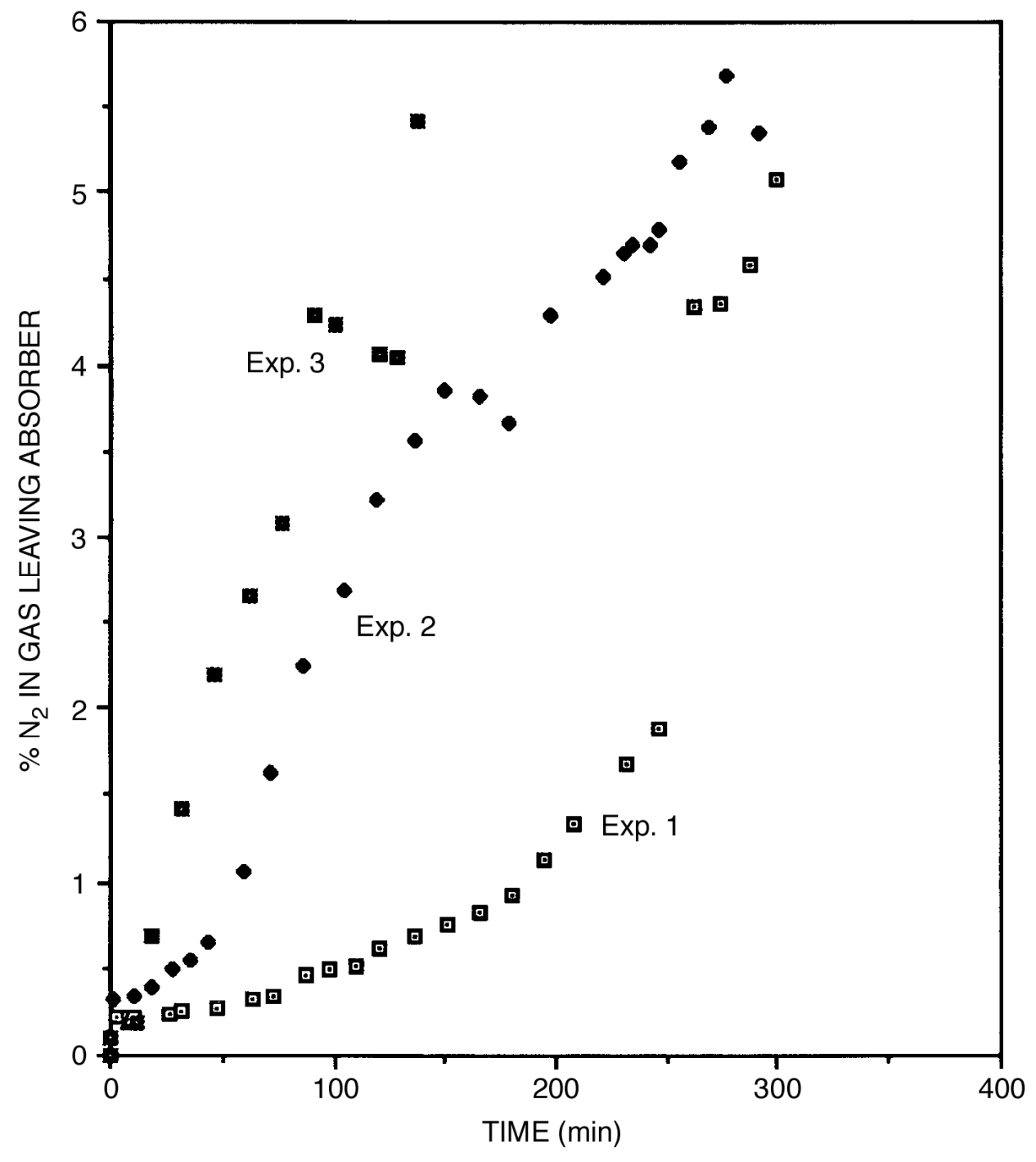

CM-7503-41

Figure 8. Nitrogen absorption profile on molybdenum phosphine complex at $200 \mathrm{psi}(\mathrm{L} / \mathrm{G}=0.6)$. 


\section{ECONOMIC ANALYSIS}

The economic analysis performed for Phase I (SRI International, 1996) showed the economic promise of the technology when it was assumed that the phosphine complex was longlived. When the adsorption experiments in the bench-scale apparatus were completed, a new economic analysis was performed to determine the effect of the potentially short lifetime of the complex. The cost to treat $1000 \mathrm{SCF}$ of natural gas was calculated for two plant sizes, $2 \mathrm{MM}$ SCFD and 75 MM SCFD, with a phosphine complex lifetime ranging from 3 months to 10 years. The 10-year lifetime calculation was expected to give approximately the same result as the Phase I calculations, which assumed a 10-year life.

\section{CALCULATION BASIS}

All parameter were kept essentially the same as in the Phase I analysis. Because the results of the bench-scale tests were confounded with the effects of inactivation and material holdup in the absorption tower, there was no reason to change the estimates of compound effectiveness that served as the basis for the Phase I analysis. The stream flows and the equipment sizes in the plants were unchanged, although the capital cost estimates were updated to reflect the current capital cost index. The operating cost continued to include the loss of methane and toluene in the vent gas and the loss of toluene in the purified gas and to neglect the cost of the subquality gas entering the process.

The cost of the phosphine compound was still estimated to be $\$ 33 / \mathrm{lb}$. This estimate was completed by assuming that production costs for specialty chemicals produced in large volumes are twice the cost of the intermediates (raw materials), as is typical in the industry. The intermediate costs, because they were predominantly specialty chemicals themselves, were taken from a laboratory supply catalog because SRI could not identify a supplier for bulk amounts. The catalog prices were reduced by a factor of 10 to get bulk prices to reflect the average difference between catalog sales and bulk sales for a number of unrelated compounds where a bulk source could be identified. This procedure is highly speculative. The phosphine compound costs could be lower, especially if its demand resulted in increased production and lowered cost for one or more of the intermediates. The phosphine compound cost could also be higher.

The lifetime of the phosphine compound in the system was varied from 3 months to 10 years. In the Phase I calculations, the phosphine compound was considered part of the capital investment and depreciated over a 10-year period, after which it would be replaced. No loss of material from daily operation was included. Calculating the cost of phosphine in this way is not 
appropriate when its lifetime (such as 3 months) is shorter than the normal capital depreciation period of 10 years. In the new calculations, the cost of replacing phosphine after its lifetime had expired was charged against each 1000 SCF treated as a raw material cost. No loss of material in waste streams from daily operation was included explicitly. This should give approximately the same result for the 10-year case, although slightly lower, since when phosphine is considered as capital it carries some of the charges related to capital construction.

In the previous calculation with a 10-year lifetime, 114,000 pounds of phosphine was charged into the system for the 75 MM SCFD case and 2500 pounds for the 2 MM SCFD case. This leads to the following consumption rates (in lb/MM SCF):

\begin{tabular}{lcc} 
& 75 MM SCFD & 2 MM SCFD \\
\cline { 2 - 3 } 3-month life & 18.76 & 15.43 \\
6-month life & 9.38 & 7.716 \\
1-year life & 4.69 & 3.858 \\
5-year life & 0.938 & 0.7716 \\
10-year life & 0.469 & 0.3858
\end{tabular}

\section{OPERATING COSTS}

Table 3 shows the results of the process economic calculations for the 3-month life, 75MM SCFD case. The calculations show three plant sizes: the base case and plants that are smaller and larger than the base case. The additional calculations for the larger and smaller plants show that the cost is not highly sensitive to plant size when the plant size is 75 MM SCFD. Table 4 shows the results of the process economic calculations for the 3-month life, 2-MM SCFD case. When the plant size is 2 MM SCFD, the operating cost is sensitive to plant size, as would be expected. The calculations are similar for the other cases, as summarized in Table 5. 
Table 3

Cost for Nitrogen Removal with Phosphine-3-Month Life, 75 MM SCFD

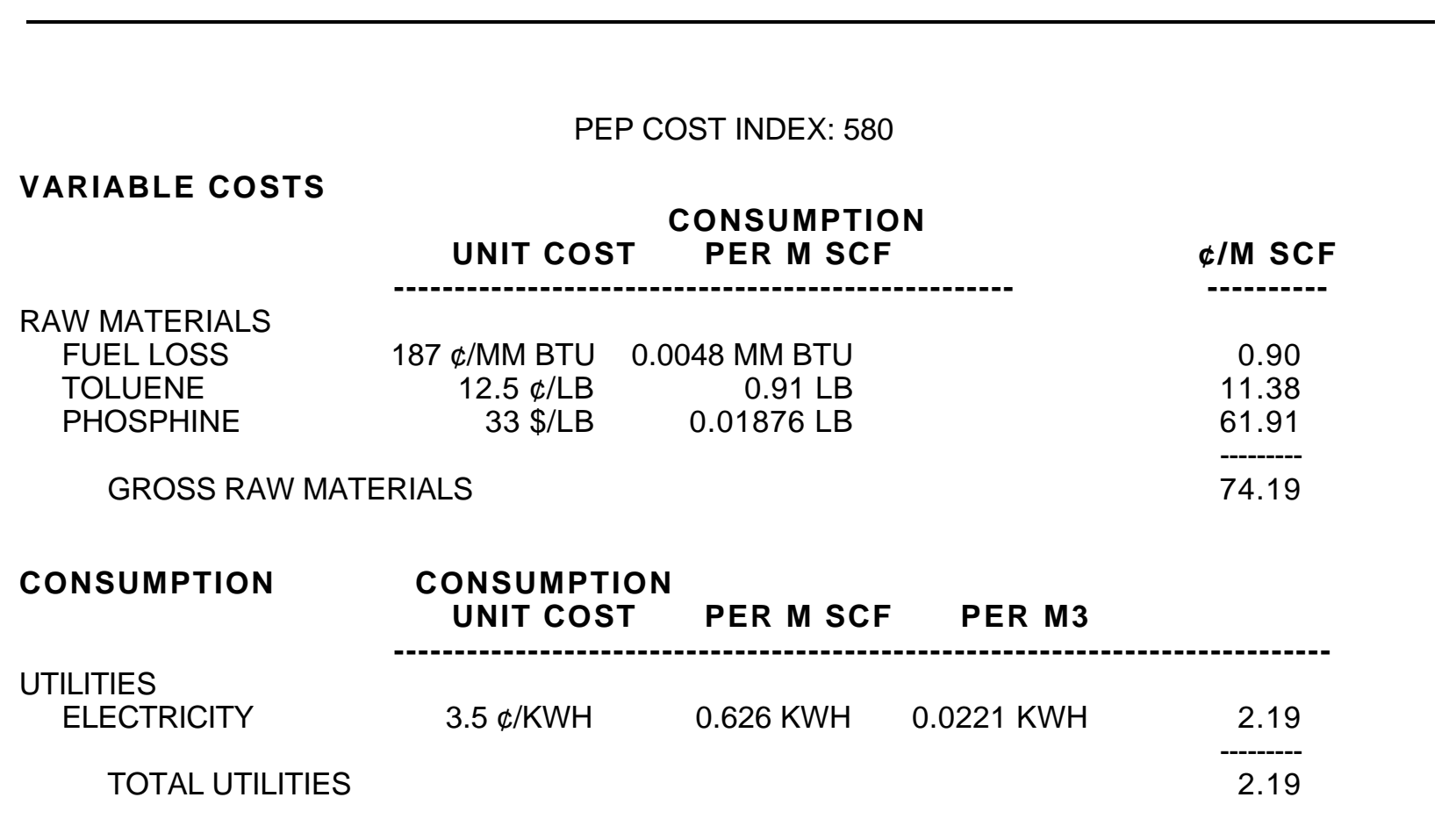


Table 3 (concluded)

Cost for Nitrogen Removal with Phosphine-3-Month Life, 75 MM SCFD

PEP COST INDEX: 580

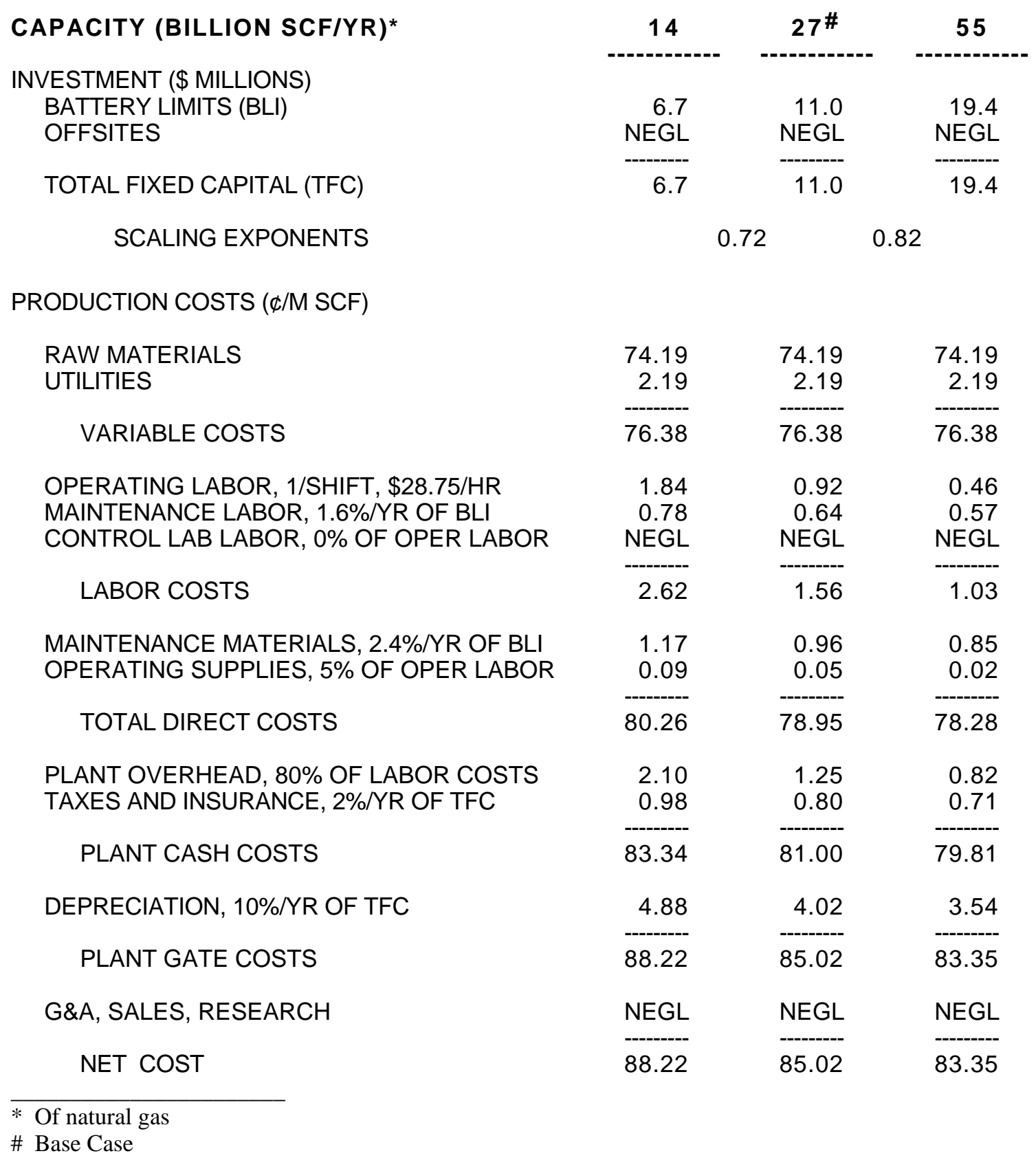


Table 4

Cost for Nitrogen Removal with Phosphine-3-Month Life, 2 MM SCFD

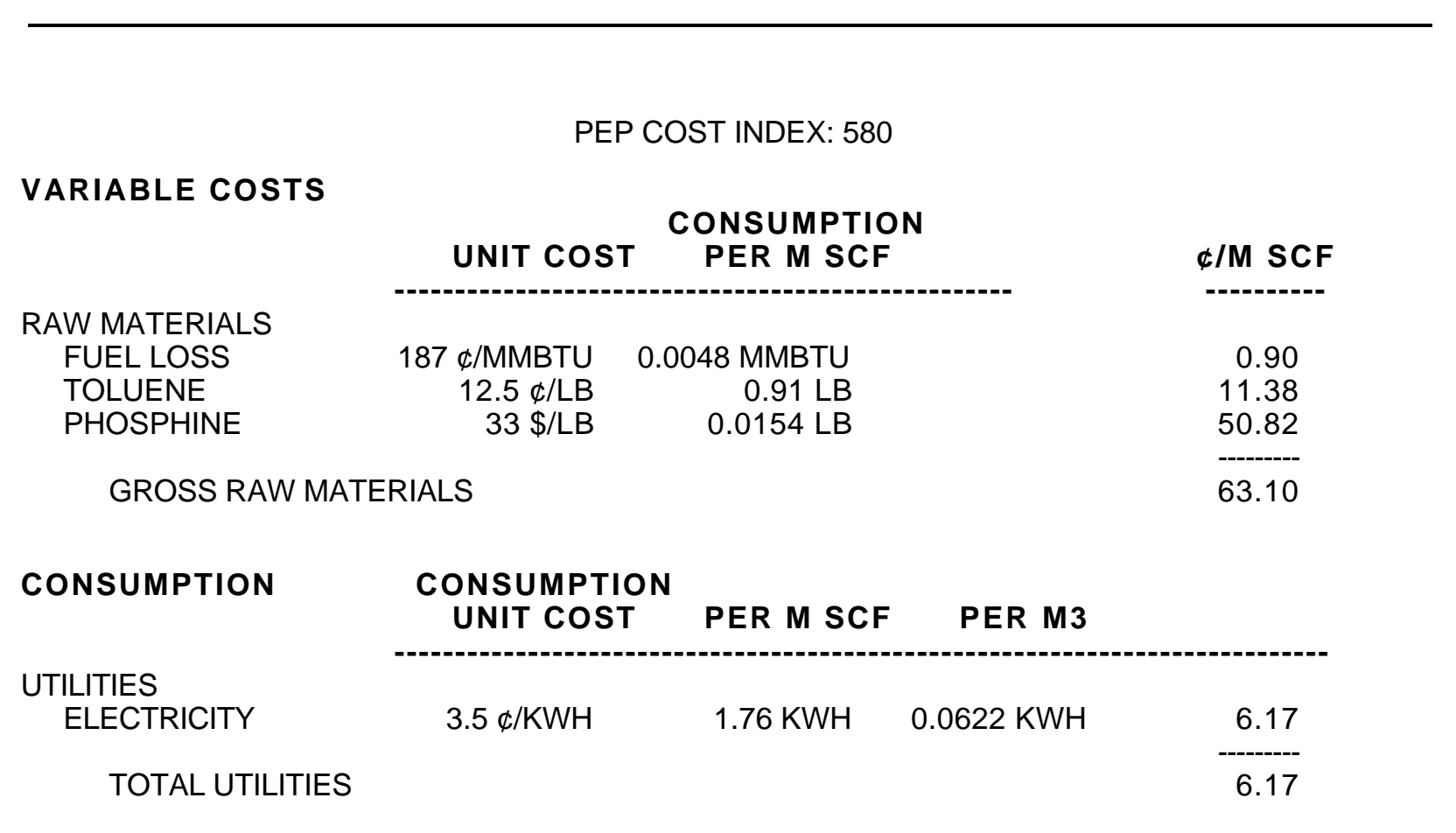


Table 4 (concluded)

Cost for Nitrogen Removal with Phosphine-3-Month Life, 2 MM SCFD

\begin{tabular}{|c|c|c|c|}
\hline \multicolumn{4}{|c|}{ PEP COST INDEX: 580} \\
\hline CAPACITY (BILLION SCF/YR)* & 0 & $1 \#$ & 1 \\
\hline $\begin{array}{l}\text { INVESTMENT (\$ MILLIONS) } \\
\text { BATTERY LIMITS (BLI) } \\
\text { OFFSITES }\end{array}$ & $\begin{array}{r}1.1 \\
N E G L\end{array}$ & $\begin{array}{r}1.6 \\
N E G L\end{array}$ & $\begin{array}{r}2.3 \\
\text { NEGL }\end{array}$ \\
\hline TOTAL FIXED CAPITAL (TFC) & 1.1 & 1.6 & 2.3 \\
\hline SCALING EXPONENTS & \multicolumn{2}{|r|}{0.53} & 0.57 \\
\hline \multicolumn{4}{|l|}{ PRODUCTION COSTS (\$/M SCF) } \\
\hline $\begin{array}{l}\text { RAW MATERIALS } \\
\text { UTILITIES }\end{array}$ & $\begin{array}{r}63.10 \\
6.17\end{array}$ & $\begin{array}{r}63.10 \\
6.17\end{array}$ & $\begin{array}{r}63.10 \\
6.17\end{array}$ \\
\hline VARIABLE COSTS & 69.27 & 69.27 & 69.27 \\
\hline $\begin{array}{l}\text { OPERATING LABOR, } 1 / \text { SHIFT, } \$ 28.75 / \mathrm{HR} \\
\text { MAINTENANCE LABOR, } 1.6 \% / \text { YR OF BLI } \\
\text { CONTROL LAB LABOR, } 0 \% \text { OF OPER LABOR }\end{array}$ & $\begin{array}{r}69.00 \\
4.78 \\
\text { NEGL }\end{array}$ & $\begin{array}{r}34.50 \\
3.45 \\
\text { NEGL }\end{array}$ & $\begin{array}{r}17.25 \\
2.56 \\
\text { NEGL }\end{array}$ \\
\hline LABOR COSTS & 73.78 & 37.95 & 19.81 \\
\hline $\begin{array}{l}\text { MAINTENANCE MATERIALS, 2.4\%/YR OF BLI } \\
\text { OPERATING SUPPLIES, 5\% OF OPER LABOR }\end{array}$ & $\begin{array}{l}7.16 \\
3.45\end{array}$ & $\begin{array}{l}5.18 \\
1.73\end{array}$ & $\begin{array}{l}3.84 \\
0.86\end{array}$ \\
\hline TOTAL DIRECT COSTS & 153.66 & 114.13 & 93.78 \\
\hline $\begin{array}{l}\text { PLANT OVERHEAD, } 80 \% \text { OF LABOR COSTS } \\
\text { TAXES AND INSURANCE, } 2 \% / Y R \text { OF TFC }\end{array}$ & $\begin{array}{r}59.02 \\
5.97\end{array}$ & $\begin{array}{r}30.36 \\
4.32\end{array}$ & $\begin{array}{r}15.85 \\
3.20\end{array}$ \\
\hline PLANT CASH COSTS & 218.65 & 148.81 & 112.83 \\
\hline DEPRECIATION, 10\%/YR OF TFC & 29.85 & 21.59 & 16.00 \\
\hline PLANT GATE COSTS & 248.50 & 170.40 & 128.83 \\
\hline G\&A, SALES, RESEARCH & NEGL & NEGL & NEGL \\
\hline NET PRODUCTION COST & 248.50 & 170.40 & 128.83 \\
\hline
\end{tabular}


Table 5

Costs for Nitrogen Removal with Phosphine for Longer Lifetimes

\begin{tabular}{|l|c|c|}
\hline $\begin{array}{l}\text { Replacement Time for } \\
\text { Phosphine Compound }\end{array}$ & $\begin{array}{c}\text { Operating Cost for 2 MM SCFD } \\
\text { Plant Size } \\
(\$ / M ~ S C F)\end{array}$ & $\begin{array}{c}\text { Operating Cost for 75 MM } \\
\text { SCFD Plant Size } \\
\text { (\$M SCF) }\end{array}$ \\
\hline 3-month life & 1.70 & 0.85 \\
\hline 6-month life & 1.45 & 0.54 \\
\hline 1-yr life & 1.32 & 0.39 \\
\hline 5-yr life & 1.22 & 0.26 \\
\hline 10-yr life & 1.20 & 0.25 \\
\hline
\end{tabular}

The previous estimated operating cost for the 10-year lifetime was $\$ 0.26 / \mathrm{M} \mathrm{SCF}$ at $75 \mathrm{MM}$ SCFD and \$1.22/M SCF at 2 MM SCFD. The operating costs drop steeply as the phosphine compound lifetime increases from 3 months to 1 year, but after that the costs are dominated by the cost of the toluene losses.

The operating costs for existing technology are between $\$ 1.0$ to $\$ 3.0 / \mathrm{M} \mathrm{SCF}$ at the small scale and $\$ 0.30 / \mathrm{M} \mathrm{SCF}$ at the larger scale. This means that, even if the phosphine compound lifetime were as short as 3 months, the absorption technology could be cost effective for small plants. For larger plants, a 5-year lifetime is required for the technology to be cost effective. 


\section{CONCLUSIONS}

The economic analysis indicated that nitrogen absorption using the molybdenum phosphine complex could be cost competitive with conventional technology if it did not degrade too rapidly in use. The bench-scale experiments conducted to demonstrate the utility of the absorption process were inconclusive because

- The phosphine compound appeared to degrade quite rapidly in the absorption system.

- Solids accumulated in the tower packing and other system dead spots.

- Some of the phosphine compound that had not reacted with nitrogen was insoluble under test conditions and interfered with filtration proposed for regeneration.

Additional experimental work is required to establish the intrinsic stability of the phosphine compound. This work should be conducted with a new batch of compound under controlled laboratory conditions to measure how rapidly it degrades when exposed to water, oxygen, and hydrogen sulfide. If a compound has a degradation lifetime that exceeds the few weeks encountered in the bench-scale work reported here, a redesigned bench-scale system or a demonstration in the field should be used to test the technology.

In the long run, however, a search for alternative absorbents should be conducted. The phosphine compound's solubility in toluene is too limited and, even if the required stability lifetime can be coaxed out of it, the special handling required may make a process that is impractical for field use. Since toluene loss is a significant component of the operating cost, the search should include looking for absorbents that work in cheaper vehicles, including water. 


\section{REFERENCES}

Changela, M.K., R.L. McKee, H. Heshan, V.K. Pathak, M.P. Quinlan, and J.F. Strickland, 1991. "Evaluation of Natural Gas Processing Technology, Topical Report," L.W. Echterhoff and G.F. Reading, Eds., GRI Report No. GRI-91/0230 (September 1991).

Echterhoff, L.W., and V.K. Pathak, 1991. "Evaluation of Process Costs for Small Scale Nitrogen Removal from Natural Gas," GRI Report No. GRI-91/0092 (February 1991).

International Critical Tables, 1928. Vol. 3, pp. 269 (McGraw-Hill, NY).

SRI International, 1996. "Nitrogen Removal from Natural Gas: Phase I," DoE Contract No. DEAC21-95MC32265 (December 1996). 
APPENDIX A

\section{DESIGN CALCULATIONS}

A- 1 


\title{
MATERIAL BALANCE CALCULATIONS FOR A NITROGEN ABSORBER
}

\author{
(Basis: 1 MM SCFD of LQNG with $20 \%$ nitrogen at 1000 psia)
}

Inlet gas composition:

Inlet gas pressure:

Inlet gas flow rate:

Exit gas composition:

Exit gas pressure:

Exit gas flow rate:
Nitrogen $-\mathrm{Y}_{\mathrm{i}}=0.2$, Methane $-1-\mathrm{Y}_{\mathrm{i}}=0.8$

Molecular weight $=18.4$

1000 psia, Inlet gas temperature $20^{\circ} \mathrm{C}$

$1 \mathrm{MM} \mathrm{SCFD}=14.62 \mathrm{gmole} / \mathrm{sec}=269 \mathrm{~g} / \mathrm{sec}$

Nitrogen $-Y_{o}=0.04$, Methane $-1-Y_{o}=0.96$

Molecular weight - 16.48

1000 psia, Exit gas temperature $-20^{\circ} \mathrm{C}$

$14.62 \times 0.8 / 0.96=12.18$ gmole $/ \mathrm{sec}$

(assuming no methane loss)

$=0.833 \mathrm{MM}$ SCFD

$=200.7 \mathrm{~g} / \mathrm{sec}$.

Moles of nitrogen removed: $14.62 \times 0.2-12.18 \times 0.04=2.44$ gmole $/ \mathrm{sec}$

Assume phosphine solubility in toluene $=60 \mathrm{mM}=$ phosphine concentration in feed toluene Assume dissolved nitrogen concentration in feed toluene $=5 \mathrm{mM}$

Assume phosphine nitrogen complex solubility in toluene $=0$ (i.e. immediate precipitation)

Nitrogen solubility $=0.113 \mathrm{M} /(\mathrm{STP}) / \mathrm{mL}$ of toluene

Henry's law constant $=\mathrm{H}=2.92 \times 10^{3} \mathrm{psi}-\mathrm{L} /$ gmole

Exit gas nitrogen partial pressure $=40$ psi

Dissolved nitrogen concentration in equilibrium with exit gas $=0.0137 \mathrm{gmole} / \mathrm{L}=13.7 \mathrm{mM}$

Feed gas nitrogen partial pressure $=200$ psi

Concentration of dissolved nitrogen in equilibrium with the feed gas $=68.5 \mathrm{mM}$

Assume 50\% nitrogen saturation of the exit toluene solution.

Therefore, concentration of dissolved nitrogen in exit toluene $=34.25 \mathrm{mM}$.

Also assume 50\% utilization of phosphine complex (based on experimental studies), resulting in immediate precipitation of the phosphine-nitrogen complex.

Therefore, amount of nitrogen removed by complexation $=30 \mathrm{mM}$

Increase in total nitrogen concentration in toluene $=34.25+30-5=59.25 \mathrm{mM}$

Toluene feed rate needed $\quad=2.44$ gmole $/ \mathrm{sec} / 59.25 \times 10^{-3} \mathrm{gmole} / \mathrm{L}$

$=41.2 \mathrm{~L} / \mathrm{sec}=39.220 \mathrm{gal} . \mathrm{hr}$

$=35.68 \mathrm{~kg} / \mathrm{sec}=387.3 \mathrm{gmoles} / \mathrm{sec}$

Dissolved nitrogen concentration in feed $=5 \times 10^{-3}$ gmoles $/ \mathrm{L}$

Mole fraction of nitrogen in toluene at gas exit location $=0.00053=X_{0}$

Dissolved nitrogen concentration in exit solution $=34.25 \times 10^{-3} \mathrm{gmoles} / \mathrm{L}$

Mole fraction of dissolved nitrogen in toluene at gas inlet location $=0.00364=X_{i}$

Total nitrogen loading in exit solution $=64.25 \times 10^{-3}$ gmoles $/ \mathrm{L}$ 


\section{Design Calculations for a Packed Column Nitrogen Absorber}

\section{Column Diameter:}

Liquid flow rate $=35.68 \mathrm{~kg} / \mathrm{sec}$

Average gas flow rate $=235 \mathrm{~g} / \mathrm{sec}$

Density of liquid $\sim 0.866 \mathrm{~g} / \mathrm{cc}$

Average molecular weight of gas $=17.44$

Average density of gas $=17.44 \times 273 \times 1000 /(22414 \times 293 \times 14.7)=0.0493 \mathrm{~g} / \mathrm{cc}$

X parameter in Figures 18-39 and 18-38 of Perry's Handbook, Fifth edition:

$=[\mathrm{L} / \mathrm{G}] \times\left(\rho_{\mathrm{g}} / \rho_{1}\right)^{0.5}=[35.68 / 0.235] \times(0.0493 / 0.866)^{0.5}=36.23$.

This X parameter value is outside the normal range of Figure 18-39, although it is within the range of the older Figure 18-38. This indicates that the L/G mass ratio (and especially the volumetric liquid to gas flow rate ratio) is much higher than is usual for a packed tower. We need to verify the applicability of these correlations at the high L/G ratios in this design.

From Figure 18-38, Y parameter at half the flooding point for $\mathrm{X}-36$ is $\sim 0.00008$.

Y parameter $=\mathrm{U}^{2} \mathrm{a}_{\mathrm{p}} \rho_{\mathrm{g}} \mu_{1}^{0.2} / \rho_{1} \mathrm{~g} \varepsilon^{3}=0.00008$

where, $\quad \mathrm{U}=$ superficial gas velocity, $\mathrm{ft} / \mathrm{sec}$

$\mathrm{a}_{\mathrm{p}}=$ Packing area $=58 \mathrm{ft}^{2} / \mathrm{ft}^{3}$ for 1 " ceramic Raschig rings

$\rho_{\mathrm{g}}=$ gas density $=3.08 \mathrm{lb} / \mathrm{ft}^{3}(0.0493 \mathrm{~g} / \mathrm{cc})$

$\mu_{1}=$ liquid viscosity $\sim 0.6 \mathrm{cp}$

$\rho_{1}=$ liquid density $=54.04 \mathrm{lb} / \mathrm{ft}^{3}(0.866 \mathrm{~g} / \mathrm{cc})$

$\mathrm{g}=$ gravitational acceleration $=32.2 \mathrm{ft} / \mathrm{sec}^{2}$, and

rings

$\varepsilon=$ fractional void space in dry packing $=0.74$ for 1 " ceramic Raschig

$\mathrm{U}=0.0187 \mathrm{ft} / \mathrm{sec}$. Volumetric average gas flow rate $=235 / 0.0493=4766.7 \mathrm{cc} / \mathrm{sec}$.

Column cross sectional area required $=4766.7 /\left(30.48^{3}\right) / 0.0187=9 \mathrm{ft}^{2}$

Column diameter required $=3.4$ feet.

This column diameter will produce liquid loading rate of $31,400 \mathrm{lb} / \mathrm{hr}-\mathrm{ft}^{2}$, which is very high.

Increase column diameter to 4 feet. Corresponding liquid rate $=22685 \mathrm{lb} / \mathrm{hr}-\mathrm{ft}^{2}$, which may still be high. Column area $=12.57 \mathrm{ft}^{2}$.

\section{Number of Overall Gas as well as Liquid Phase Mass Transfer Units}

\section{Gas Phase Overall Mass Transfer Units:}

Feed $\mathrm{N}_{2}$ concentration $=0.2 \mathrm{Y}_{1} \quad$ Exit $\mathrm{N}_{2}$ concentration $=0.04=\mathrm{Y}_{\mathrm{o}}$

At gas inlet $\mathrm{X}_{1}=0.00364$, corresponding $\mathrm{Y}_{\mathrm{i}}{ }^{\circ}=0.1$ 
At gas exit $\mathrm{X}_{\mathrm{o}}=0.00053$, corresponding $\mathrm{Y}_{\mathrm{o}}{ }^{\circ}=0.0146$

Assuming linear operating and equilibrium lines $\mathrm{N}_{\mathrm{OG}}=2.94 \sim 2$

\section{Liquid Phase Overall Mass Transfer Units:}

At gas inlet, $X_{1}=0.00364 \quad$ At gas exit $X_{o}=0.00053$

At gas inlet feed $\mathrm{N}_{2}$ concentration $=0.2=\mathrm{Y}_{\mathrm{i}}$, Corresponding $\mathrm{X}_{\mathrm{i}}^{\circ}=0.00729$

At gas exit $\mathrm{N}_{2}$ concentration $=0.04=\mathrm{Y}_{\mathrm{o}}$, Corresponding $\mathrm{X}_{\mathrm{o}}^{\circ}=0.00146$

Again assuming linear operating and equilibrium lines $\mathrm{N}_{\mathrm{OL}}=1.56 \sim 2$

\section{Liquid Phase Height of Transfer Unit:}

Liquid flow rate $=35.68 \mathrm{~kg} / \mathrm{sec}$, Column cross sectional area $=12.57 \mathrm{ft}^{2}$

Liquid loading rate $=\mathrm{L}=22,480 \mathrm{lb} / \mathrm{hr}-\mathrm{ft}^{2}$. Gas loading rate $=\mathrm{G}=148 \mathrm{lb} / \mathrm{hr}^{-\mathrm{ft}^{2}}$.

Number of correlations is available in Perry's Handbook (Fifth edition)

1) Eq. 18-50:

$$
H_{L}=(1 / \alpha)\left(L / \mu_{1}\right)^{n}\left(\mu_{1} / D_{1} \rho_{1}\right)^{0.5}
$$

where $\alpha=100$ and $n=0.22$ for 1 -inch Raschig rings packing

$\mathrm{L}=$ liquid rate $=22480 \mathrm{lb} / \mathrm{hr}^{-\mathrm{ft}^{2}}$

$\mu_{1}=$ liquid viscosity $\sim 1.5 \mathrm{lb} / \mathrm{ft}-\mathrm{hr}(\sim 0.62 \mathrm{cp})$

$\mathrm{D}_{1}=$ diffusivity of nitrogen in toluene $\sim 7.75 \times 10^{-5} \mathrm{ft}^{2} / \mathrm{hr}\left(2 \times 10^{-5} \mathrm{~cm}^{2} / \mathrm{sec}\right)$

$\rho_{1}=$ liquid density $=54.04 \mathrm{lb} / \mathrm{ft}^{3}$

$\mathrm{H}_{\mathrm{L}}=1.57$ feet

2) From Figure $18-62, \mathrm{H}_{\mathrm{L}} \sim 2$ feet for $\mathrm{L}=22,000 \mathrm{lb} / \mathrm{hr}-\mathrm{ft}^{2}$

3) From Figure $18.65,18.66, \mathrm{H}_{\mathrm{L}} \sim 0.15 \mathrm{x}\left(\mu_{1} / \mathrm{D}_{1} \rho_{1}\right)^{0.5} \sim 2.9$ feet.

All three correlations agree reasonably well. $\mathrm{H}_{\mathrm{L}}$ value may conservatively be assumed to be about 3 feet. For number of transfer units $=2$, the total packing height is predicted to be about 5 feet based on liquid phase mass transfer alone. 


\section{Gas Phase Height of Transfer Unit}

1) From Eq. 18-59 of Perry's Handbook (Fifth edition):

$$
\mathrm{HG}=\varphi \mathrm{Sc}_{\mathrm{g}}{ }^{0.5}(\mathrm{D})^{1.24}(\mathrm{Z} / 10)^{0.333} /\left(\mathrm{L} \mathrm{f}_{1} \mathrm{f}_{2} \mathrm{f}_{3}\right)^{0.5}
$$

where $\varphi=110$ for 1 -inch Raschig rings packing

$\mathrm{Sc}_{\mathrm{g}}=$ Schmidt number for gas phase

$\mu_{\mathrm{g}}=$ gas phase viscosity $=0.0108 \mathrm{cp}$ (need to include effect of pressure)

$\mathrm{D}_{\mathrm{g}}=$ diffusivity of nitrogen in methane $\sim 0.15 /(1000 / 14.7) \sim 0.0022 \mathrm{~cm}^{2} / \mathrm{sec}$

$\rho_{\mathrm{g}}=$ gas density $=0.0493 \mathrm{~g} / \mathrm{cm}^{3}$

$\mathrm{Sc}_{\mathrm{g}}=0.000108 / 0.493 / 0.0022=1.0$

$\mathrm{D}=$ column diameter, $\mathrm{ft}$. Effect of $\mathrm{D}$ is limited to only $2 \mathrm{ft}$.

$\mathrm{L}=22,480 \mathrm{lb} / \mathrm{hr}-\mathrm{ft}^{2}$

$\mathrm{f}_{1}=\left(\mu_{1} / 2.42\right)^{0.16}=(1.5 / 2.42)^{0.16}=0.926$

$f_{2}=\left(62.4 / \rho_{1}\right)^{1.25}=(62.4 / 54.04)^{1.25}=1.196$

$\mathrm{f}_{3}=(72.8 / \sigma)^{0.8}=(72.8 / 28)^{0.8}=2.148$

$\mathrm{Z}=$ Packed height, feet, $\sim$ assume $10 \mathrm{ft}$

$\mathrm{H}_{\mathrm{G}}=1.1$ foot

2) From Figure 18078 for ammonia-water system:

$\mathrm{H}_{\mathrm{OG}} \sim 0.6$ feet for 1-inch Raschig rings. Also Figures 18-80, 18-81 show similar values.

3) Figure 18-91 for $\mathrm{CO}_{2}$-water system provides gas phase mass transfer coefficient.

For 1-inch Raschig ring packings at $\mathrm{L}=22,000, \mathrm{~K}_{\mathrm{g}} \mathrm{a} \sim 9 \mathrm{lb} / \mathrm{hr}-\mathrm{ft}^{3}-\mathrm{atm}$. The height of transfer unit is given by $\mathrm{H}_{\mathrm{OG}}=\mathrm{G} / \mathrm{K}_{\mathrm{g}} \mathrm{a}=148 /(9 \times 1000 / 14.7) \sim 0.24$ feet.

Although data presented in these graphs are for different systems, they are of the same order as the value calculated from Eq. 18.59 of about 1.1 feet. 
The heights of transfer units for gas and liquid phase mass transfer may be combined to obtain an overall height of transfer unit:

$$
\mathrm{H}_{\mathrm{OG}}=\mathrm{H}_{\mathrm{G}}+\left(\mathrm{G}_{\mathrm{m}} \mathrm{m} / \mathrm{L}_{\mathrm{m}}\right) \mathrm{H}_{\mathrm{L}}
$$

where $L_{m}$ and $G_{m}$ are molar flow rates of respective phases, and $m$ is the slope of the equilibrium line. For the present system, $\mathrm{L}_{\mathrm{m}} / \mathrm{G}_{\mathrm{m}} \sim(22480 / 92.13) /(148 / 17.44) \sim 28.75$ and $\mathrm{m} \sim 27.5$ (from Henry's law constant and toluene molar volume).

Therefore, $\mathrm{H}_{\mathrm{OG}} \sim \mathrm{H}_{\mathrm{L}}+\mathrm{H}_{\mathrm{G}} \sim 3+1 \sim 4 \mathrm{ft}$.

The total packing height based on overall gas phase mass transfer is calculated to be $\mathrm{H}=\mathrm{H}_{\mathrm{OG}} \mathrm{N}_{\mathrm{OG}}=$ about 12 feet. 


\section{APPENDIX B}

COMPLETE DATA FROM EXPERIMENTS CONTACTING THE MOL YBDENUM COMPLEX WITH AN ARTIFICIAL NATURAL GAS CONTAINING NITROGEN 
First Experiment:

Inlet Gas Flowrate: 0.4 SLPM

Inlet Liquid Flowrate: $240 \mathrm{~mL} / \mathrm{min}$ $\mathrm{L} / \mathrm{G}=0.6$ using $5 \mu \mathrm{M}$ filter
Date: $9 / 25 / 98$

Composition: $20 \% \mathrm{~N}_{2} / 80 \% \mathrm{CH}_{4}$

Drain Pump Flowrate: $260 \mathrm{~mL} / \mathrm{min}$

System Pressure: 200 psig

\begin{tabular}{cccccc} 
Time $(\mathrm{min})$ & $\mathrm{P}_{\mathrm{gi}}(\mathrm{psi})$ & $\mathrm{P}_{\mathrm{li}}(\mathrm{psi})$ & Diff. $\mathrm{P}$ & $\mathrm{NN}_{2}$ & $\% \mathrm{CH}_{4}$ \\
\hline $0: 0$ & 194 & 193 & 0.4 & 0.25 & 99.8 \\
$3: 22$ & 188 & 188 & 10.0 & 0.22 & 99.8 \\
$6: 52$ & 188 & 188 & $\mathrm{OL}$ & $\mathrm{NA}$ & $\mathrm{NA}(1)$ \\
$7: 52$ & 187 & 186 & 0.7 & 0.22 & 99.8 \\
$10: 52$ & 187 & 186 & 20.0 & 0.24 & 99.7 \\
$11: 10$ & 187 & 186 & $\mathrm{OL}$ & $\mathrm{NA}$ & $\mathrm{NA}(2)$ \\
$14: 45$ & 184 & 183 & 0.86 & 0.22 & 99.8 \\
$18: 08$ & 184 & 183 & 3.0 & 0.24 & $99.7(3)$ \\
$21: 38$ & 184 & 183 & 0.7 & 0.26 & 99.4 \\
$32: 10$ & 184 & 183 & 0.77 & 0.26 & 99.4 \\
$39: 10$ & 186 & 186 & 0.74 & 0.26 & 99.6 \\
$47: 50$ & 188 & 187 & 0.7 & 0.27 & 99.4 \\
$54: 55$ & 189 & 189 & 0.7 & 0.28 & 99.7 \\
$63: 33$ & 191 & 191 & 0.7 & 0.32 & 99.6 \\
$72: 20$ & 193 & 192 & 0.7 & 0.35 & 100.8 \\
$87: 00$ & 196 & 196 & 0.7 & 0.46 & $99.7(4)$ \\
$98: 00$ & 198 & 198 & 0.7 & 0.50 & 99.8 \\
$109: 30$ & 200 & 200 & 0.7 & 0.51 & 99.7 \\
$120: 00$ & 203 & 202 & 0.77 & 0.61 & 99.7 \\
$136: 11$ & 206 & 206 & 0.72 & 0.68 & 99.6 \\
$150: 56$ & 207 & 206 & 0.75 & 0.75 & 99.6 \\
$165: 30$ & 209 & 208 & 0.75 & 0.83 & 99.5 \\
$180: 00$ & 205 & 203 & 0.76 & 0.93 & 99.5 \\
$195: 00$ & 205 & 204 & 0.75 & 1.14 & $99.1(5)$ \\
$208: 35$ & 205 & 204 & 0.75 & 1.34 & 98.8 \\
$232: 00$ & 205 & 204 & 0.75 & 1.68 & 98.6 \\
$247: 00$ & 205 & 204 & 0.75 & 1.88 & 98.3 \\
$262: 00$ & 205 & 205 & 0.7 & 4.34 & 95.86 \\
$274: 00$ & 208 & 207 & 0.7 & 4.36 & 95.9 \\
$287: 00$ & 205 & 204 & 0.75 & 4.58 & 95.5 \\
$300: 00$ & 205 & 204 & 0.75 & 5.08 & $95.0(6)$
\end{tabular}

(1) Differential pressure was high (over the limit, above $22 \mathrm{psi}$ ). Operation was temporarily stopped. Filtration unit was depressurized and disassembled.

Molybdenum solids were mostly collected on the filter. Almost no yellow precipitate was collected. After regeneration (heating + agitation), solids were transferred into the holding tank. Filtration unit was put together and assembled back into the system.

Operation was restarted. 
(2) Differential pressure went over the limit. Same procedure as 1 was attempted. Once again, mostly molybdenum solids and trace amounts of $\mathrm{N}_{2}$ - bound (yellow) solids were collected on the filter.

(3) Differential pressure was high. Operation was temporarily stopped. The filter was taken off line and replaced by a $20-\mu \mathrm{M}$ filter. And the process was restarted. Only purple solids and small amounts of yellow precipitates were collected. After regeneration (heating + agitation), solids were transferred into the holding tank and then filtration unit was put together and the operation was restarted.

(4) Since we did not observe any change in the differential pressure after approximately 70 minutes, we decided to take the filtration unit off line and check for any precipitates collected on the filter. However, we did not find any yellow precipitates on the filter. Only a small amount of purple solids (unbound) were collected. Solids were pumped back into the system. Filter was put in line and the operation restarted.

(5) Filter was examined once again, and no solids were collected.

(6) The operation was terminated and the apparatus was depressurized. During the depressurization using the back pressure regulator, some of the complex was lost through the gas outlet. However, the lost amount was never quantified. We estimated the amount to be approximately between 1-2 Lit. The rest of the complex was transferred into the feed tank and stored under pure methane pressure at $200 \mathrm{psig}$. 
Second Experiment:

Date: $10 / 01 / 98$

Inlet Gas Flowrate: 0.4 SLPM Composition: $20 \% \mathrm{~N}_{2} / 80 \% \mathrm{CH}_{4}$

Inlet Liquid Flowrate: $240 \mathrm{~mL} / \mathrm{min}$ Drain Pump Flowrate: $260 \mathrm{~mL} / \mathrm{min}$

$\mathrm{L} / \mathrm{G}=0.6$ using $20 \mu \mathrm{M}$ filter $\quad$ System Pressure: $200 \mathrm{psig}$

\begin{tabular}{rllccc} 
Time $(\mathrm{min})$ & $\mathrm{P}_{\mathrm{gi}}(\mathrm{psi})$ & $\mathrm{P}_{\mathrm{li}}(\mathrm{psi})$ & Diff. $\mathrm{P}$ & $\% \mathrm{~N}_{2}$ & $\% \mathrm{CH}_{4}$ \\
\hline $1: 45$ & 203 & 202 & 0.9 & 0.32 & 99.9 \\
$10: 09$ & 202 & 202 & 0.8 & 0.32 & 100.0 \\
$18: 54$ & 201 & 200 & 0.8 & 0.39 & $101.0(1)$ \\
$27: 41$ & 200 & 199 & 0.8 & 0.49 & 99.7 \\
$35: 55$ & 199 & 199 & 0.8 & 0.54 & 99.4 \\
$43: 34$ & 200 & 200 & 0.8 & 0.66 & 99.3 \\
$60: 00$ & 201 & 200 & 0.9 & 1.06 & 98.9 \\
$71: 31$ & 201 & 201 & 0.9 & 1.64 & 99.4 \\
$86: 00$ & 202 & 201 & 0.9 & 2.24 & 98.8 \\
$104: 00$ & 203 & 203 & 0.9 & 2.69 & 98.3 \\
$118: 57$ & 204 & 203 & 0.9 & 3.23 & 97.7 \\
$136: 22$ & 203 & 203 & 0.9 & 3.57 & 97.4 \\
$149: 10$ & 206 & 205 & 0.9 & 3.86 & $97.1(2)$ \\
$156: 23$ & 198 & 195 & 0.9 & 4.00 & $96.8(3)$ \\
$165: 38$ & 201 & 199 & 0.4 & 3.83 & 96.7 \\
$179: 00$ & 204 & 203 & 0.4 & 3.67 & 96.9 \\
$198: 00$ & 201 & 200 & 0.7 & 4.28 & $95.7(4)$ \\
$221: 00$ & 200 & 200 & 20 & 4.51 & $94.5(5)$ \\
$230: 00$ & 203 & 201 & 0.9 & 4.65 & $94.4(6)$
\end{tabular}

(1) Nitrogen flow was started.

(2) Since we did not observe any change in the differential pressure, a regeneration procedure was performed to check if any solids have been collected on the filter. No trace of solids on the filter. The filtration unit was placed in line and operation was restarted.

(3) There was a noise in the nitrogen peak.

(4) Another regeneration procedure was carried out to check for solids. No solids were collected. 
(5) Since the differential pressure was high (20 psi), another regeneration procedure was carried out. Unbound solids and some yellow precipitates were collected. After regeneration (heating + agitation), solids were transferred into the holding tank and then filtration unit was put together and the operation was restarted.

(6) The operation was terminated and the apparatus was depressurized. All of the complex was transferred into the feed tank which was stored under pure methane pressure at 200 psig.

(7) Between the second and the third experiments, we attempted another 200 psig experiment. Right at the beginning of the experiment a liquid line right after the filtration unit was popped out of its fitting. We estimated the loss to approximately 1.5 Lit of the complex. Luckily, this happened inside of the dry glove box. Therefore, air never came into contact with the complex. We were able to proceed with the complex experiments once the liquid line and the fitting was replaced and pressure tested. 
Third Experiment:

Inlet Gas Flowrate: 0.4 SLPM

Inlet Liquid Flowrate: $240 \mathrm{~mL} / \mathrm{min}$

$\mathrm{L} / \mathrm{G}=0.6$ using $20 \mu \mathrm{M}$ filter
Date: $10 / 4 / 98$

Composition: $20 \% \mathrm{~N}_{2} / 80 \% \mathrm{CH}_{4}$

Drain Pump Flowrate: $260 \mathrm{~mL} / \mathrm{min}$

System Pressure: 400 psig

\begin{tabular}{|c|c|c|c|c|c|}
\hline Time (min) & $\mathrm{P}_{\mathrm{gi}}(\mathrm{psi})$ & $\mathrm{P}_{\mathrm{li}}(\mathrm{psi})$ & Diff. P & $\% \mathrm{~N}_{2}$ & $\% \mathrm{CH}_{4}$ \\
\hline $0: 0$ & 400 & 398 & 1.1 & 0.47 & 99.6 \\
\hline $0: 48$ & 400 & 398 & 1.1 & 0.1 & 100.2 \\
\hline $10: 00$ & 379 & 375 & 1.4 & 0.19 & 99.9 \\
\hline $17: 30$ & 375 & 371 & 1.4 & 0.19 & 99.9 \\
\hline $25: 40$ & 375 & 372 & 1.8 & 0.24 & 99.7 \\
\hline $38: 22$ & 382 & 379 & 1.2 & 0.47 & 99.4 \\
\hline $55: 49$ & 381 & 378 & 1.2 & 0.68 & $93.5(1)$ \\
\hline $70: 32$ & 379 & 377 & 1.3 & 0.89 & 99.3 \\
\hline $82: 37$ & 380 & 377 & 1.2 & 1.16 & 98.8 \\
\hline $95: 20$ & 378 & 376 & 1.2 & 1.41 & 98.5 \\
\hline 110:00 & 377 & 375 & 1.3 & 1.61 & $98.3(2)$ \\
\hline $124: 18$ & 380 & 386 & OL & 2.17 & $7.7(3)$ \\
\hline 140:20 & 376 & 370 & 1.1 & 2.29 & 97.7 \\
\hline 153:00 & 374 & 371 & 1.1 & 2.32 & 97.7 \\
\hline 169:17 & 373 & 370 & 1.0 & 2.29 & 97.7 \\
\hline $186: 19$ & 375 & 372 & 1.05 & 2.33 & 97.6 \\
\hline 200:00 & 377 & 374 & 1.20 & 2.42 & 97.5 \\
\hline 219:00 & 376 & 374 & 1.20 & 2.53 & 97.4 \\
\hline 240:00 & 377 & 374 & 1.1 & 2.72 & 97.2 \\
\hline 290:00 & 377 & 374 & 1.1 & 3.02 & 97.0 \\
\hline $333: 00$ & 375 & 372 & 1.0 & 3.51 & 96.2 \\
\hline $341: 56$ & 371 & 367 & 1.0 & 3.61 & $96.4(4)$ \\
\hline 358:00 & 369 & 366 & 0.9 & 3.58 & 96.3 \\
\hline 369:00 & 369 & 366 & 0.9 & 3.89 & 96.1 \\
\hline 379:00 & 368 & 365 & 1.0 & 3.87 & 96.1 \\
\hline $394: 00$ & 369 & 367 & 1.0 & 4.03 & 95.9 \\
\hline 411:03 & 366 & 362 & 0.9 & 4.24 & $95.7(5)$ \\
\hline
\end{tabular}

(1) Regeneration procedure was performed to check for solids (yellow + purple). No solids were collected on the fillter.

(2) Liquid got carried over to the gas lines. The trap before the chromatograph was full. The operation was temporarily stopped and the trap was evacuated. The system was restarted. Approximately $500 \mathrm{~mL}$ of the complex was lost through the trap.

(3) Another regeneration was performed. Only purple solids (unbound molybdenum) were collected on the filter. Solids were pumped back in the system and the operation was restarted. 
(4) Another regeneration was performed to check for solids. Still no solids were collected on the filter.

(5) The operation was terminated and the apparatus was depressurized. The entire complex was transferred into the feed tank and stored under pure methane pressure at 200 psig. 
Fourth Experiment:

Inlet Gas Flowrate: 0.4 SLPM

Inlet Liquid Flowrate: $240 \mathrm{~mL} / \mathrm{min}$

$\mathrm{L} / \mathrm{G}=0.6$ using $20 \mu \mathrm{M}$ filter
Date: $10 / 6 / 98$

Composition: $20 \% \mathrm{~N}_{2} / 80 \% \mathrm{CH}_{4}$

Drain Pump Flowrate: $260 \mathrm{~mL} / \mathrm{min}$

System Pressure: 400 psig

\begin{tabular}{cccccc} 
Time $(\mathrm{min})$ & $\mathrm{P}_{\mathrm{gi}}(\mathrm{psi})$ & $\mathrm{P}_{\mathrm{li}}(\mathrm{psi})$ & Diff. $\mathrm{P}$ & $\% \mathrm{~N}_{2}$ & $\% \mathrm{CH}_{4}$ \\
\hline $1: 15$ & 394 & 392 & 0.8 & 1.58 & $99.5(1)$ \\
$8: 19$ & 383 & 381 & 0.8 & 0.37 & 100.1 \\
$19: 00$ & 384 & 381 & 0.8 & 0.56 & 99.4 \\
$30: 00$ & 381 & 378 & 0.8 & 0.87 & 99.1 \\
$43: 40$ & 379 & 376 & 0.8 & 1.13 & 99.2 \\
$60: 00$ & 377 & 375 & 0.85 & 1.38 & $98.7(2)$ \\
$77: 00$ & 376 & 373 & 0.85 & 1.73 & 98.2 \\
$98: 00$ & 376 & 373 & 0.85 & 2.01 & 97.9 \\
$112: 00$ & 374 & 372 & 0.85 & 2.3 & 97.7 \\
$131: 00$ & 372 & 368 & 0.85 & 2.55 & 97.4 \\
$152: 00$ & 370 & 367 & 0.75 & 2.77 & 97.2 \\
$172: 00$ & 369 & 366 & 0.75 & 2.80 & 97.2 \\
$187: 00$ & 365 & 364 & 0.75 & 2.91 & 97.1 \\
$217: 00$ & 389 & 388 & 0.85 & 3.2 & 96.8 \\
$233: 00$ & 389 & 387 & 0.85 & 3.14 & 96.8 \\
$243: 00$ & 387 & 386 & 0.7 & 3.18 & 96.8 \\
$255: 00$ & 387 & 384 & 0.7 & 3.34 & 96.6 \\
$269: 00$ & 387 & 384 & 0.85 & 3.38 & 96.5 \\
$296: 00$ & 391 & 387 & 0.85 & 3.54 & 96.4 \\
$327: 00$ & 392 & 389 & 0.85 & 3.60 & $96.3(3)$ \\
$342: 00$ & 389 & 387 & 0.85 & 3.69 & 96.2 \\
$362: 00$ & 389 & 387 & 0.85 & 3.77 & 96.2 \\
$381: 00$ & 389 & 386 & $0 \mathrm{~L}$ & 3.92 & $96.0(4)$ \\
$385: 00$ & 385 & 381 & 17.5 & 4.06 & 95.9 \\
$400: 00$ & 385 & 382 & 10.0 & 4.29 & $95.7(5)$
\end{tabular}

(1) There was a noise on the nitrogen peak.

(2) Regeneration was performed to check for solids. No yellow or purple solids were collected on the filter. 
(3) Another regeneration was performed. There wasn't any yellow or purple precipitate on the filter.

(4) High differential pressure across the filtration unit. Filter was taken off line. Purple solids and small amount $(<10 \%)$ of yellow precipitate was collected. The solution was regenerated (heating + agitation), solids were transferred into the holding tank and then filtration unit was put together and the operation was restarted.

(5) The operation was terminated and the apparatus was depressurized. Once again some of the complex $(\sim 500 \mathrm{~mL})$ was lost during the depressurization. The entire complex was transferred into the feed tank which was stored under pure methane pressure at 200 psig. 
Fifth Experiment: Performing the more vigorous regeneration technique

Date: $10 / 19 / 98$

Inlet Gas Flowrate: 0.4 SLPM Composition: $20 \% \mathrm{~N}_{2} / 80 \% \mathrm{CH}_{4}$

Inlet Liquid Flowrate: $240 \mathrm{~mL} / \mathrm{min}$ Drain Pump Flowrate: $260 \mathrm{~mL} / \mathrm{min}$

$\mathrm{L} / \mathrm{G}=0.6 \mathrm{using} 20 \mu \mathrm{M}$ filter $\quad$ System Pressure: $200 \mathrm{psig}$

\begin{tabular}{rlllll} 
Time $(\mathrm{min})$ & $\mathrm{P}_{\mathrm{gi}}(\mathrm{psi})$ & $\mathrm{P}_{\mathrm{li}}(\mathrm{psi})$ & Diff. $\mathrm{P}$ & $\%_{2}$ & $\% \mathrm{CH}_{4}$ \\
\hline $0: 30$ & 207 & 206 & 0.71 & 0.19 & 99.9 \\
$7: 30$ & 209 & 208 & 4.4 & 0.21 & 99.8 \\
$12: 00$ & 204 & 203 & $\mathrm{OL}$ & 0.19 & $99.8(1)$ \\
$18: 30$ & 202 & 201 & 0.45 & 0.68 & $95.0(2)$ \\
$32: 00$ & 205 & 205 & 0.45 & 1.43 & 94.3 \\
$47: 00$ & 207 & 207 & 0.60 & 2.20 & 94.3 \\
$62: 00$ & 208 & 207 & 0.60 & 2.65 & 94.3 \\
$77: 00$ & 208 & 207 & 0.60 & 3.08 & 94.0 \\
$92: 00$ & 205 & 204 & 0.55 & 4.29 & $93.4(3)$ \\
$100: 00$ & 205 & 204 & 0.55 & 4.24 & 93.4 \\
$120: 00$ & 205 & 204 & 0.55 & 4.24 & 93.9 \\
$138: 00$ & 200 & 198 & 0.55 & 5.41 & $92.5(4)$
\end{tabular}

(1) Differential pressure across the filter was over the limit (22psi). Regeneration procedure was performed. Only brown solids and very small amounts of yellow precipitates were collected on the filter. Dry toluene was added to the solids with heating and agitation. Yellow (nitrogen bound) solids retained their color and never changed to purple. After attempting regeneration (heating + agitation), solids were transferred into the holding tank and then filtration unit was put together and the operation was restarted. Membrane filter was switched to $80 \mu \mathrm{m}$.

(2) There was a noise in the methane peak.

(3) Another regeneration procedure was performed to check for solids. No yellow or purple solids were collected on the membrane filter.

(4) The operation was terminated and the apparatus was depressurized. All of the complex was transferred into the feed tank which was stored under pure methane pressure at 200 psig. 
APPENDIX C

GAS CHROMATOGRAPH PARAMETERS AND SAMPLE CHROMATOGRAM

C-1 
GC Make/Model: Hewlett Packard 5890

Detector type: Thermal conductivity detector (TCD)

Column: $8 \mathrm{ft} \times 1 / 8$ inch OD, stainless steel

Packing: Heysep D, 100-120

Carrier and Reference gas type: $99.999 \%$ Helium (WESCO)

Oven Temperature: $50^{\circ} \mathrm{C}$

Detector Temperature: $110^{\circ} \mathrm{C}$

Carrier Gas flowrate: $30 \mathrm{~mL} / \mathrm{min}$

Reference Gas Flowrate: $45 \mathrm{~mL} / \mathrm{min}$

Sample gas flowrate: $30 \mathrm{~mL} / \mathrm{min}$

Run Time: 3 minutes

Using a 100-SCCM mass flow controller (model $5890 \mathrm{E}$, Brooks instrument), a metered amount $(30 \mathrm{~mL} / \mathrm{min})$ of the treated gas (outlet from the absorber, some mixture of methane and nitrogen) is sent to the GC. The gas is then carried through the column with the carrier gas, which is sent to the TCD detector for analysis in reference to the reference gas. The GC is interfaced with a computer using the GC Workmate 2.0 software (Willstein Software).

Figure $\mathrm{Cl}$ is a sample of a chromatogram for a sample stream containing $80 \% \mathrm{CH}_{4}$ / $20 \% \mathrm{~N}_{2}$. The peak with a retention time of approximately $0.65 \mathrm{~min}$ is nitrogen. The methane peak has a retention time of approximately $1.09 \mathrm{~min}$. Figure $\mathrm{C} 2$ is a sample of a chromatogram for a sample stream containing $99 \% \mathrm{CH}_{4} / 1 \% \mathrm{~N}_{2}$. 


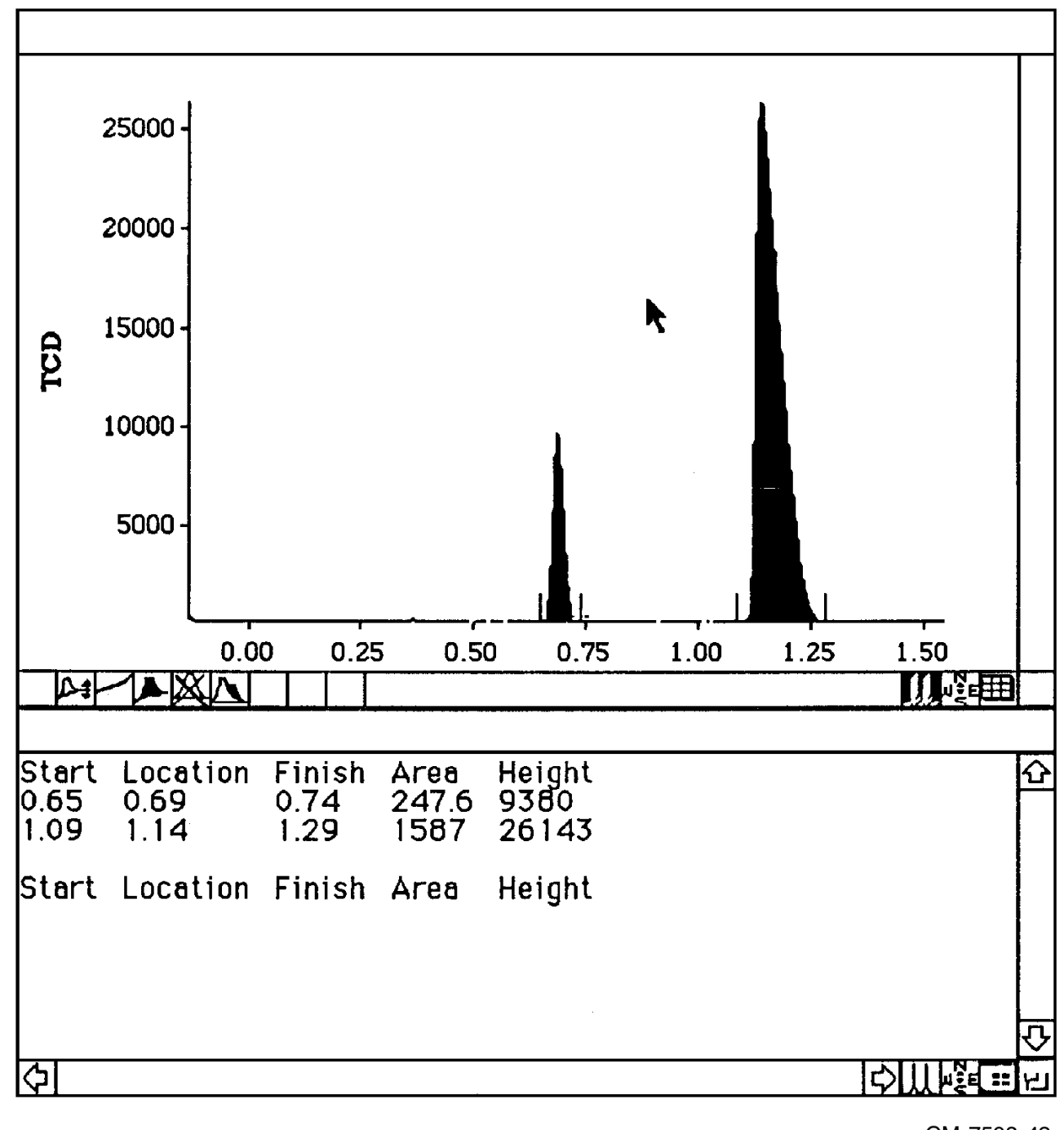

CM-7503-42

Figure C-1. Chromatogram of a $80 \% \mathrm{CH}_{4} / 20 \% \mathrm{~N}_{2}$ stream. 


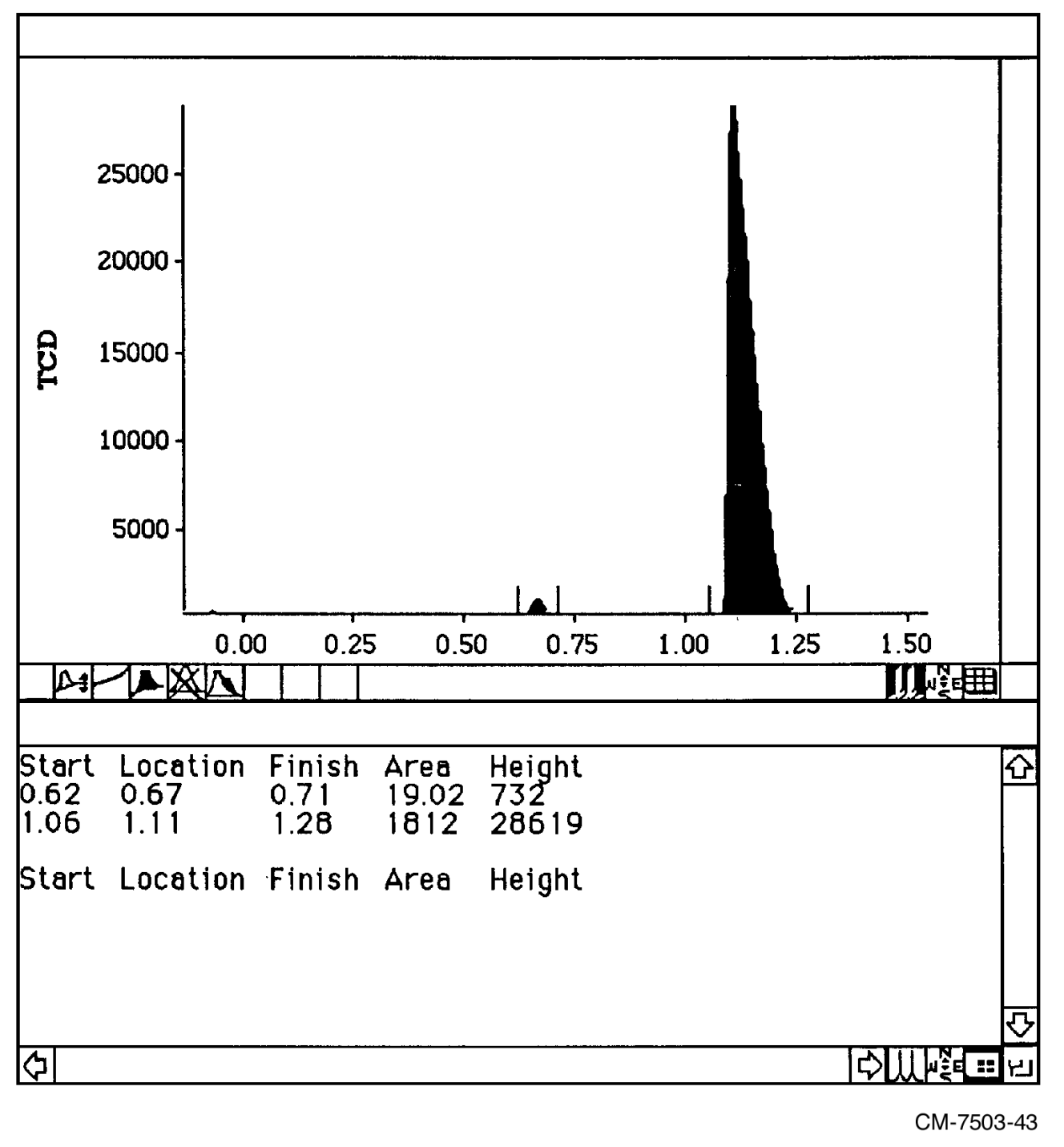

Figure C-2. Chromatogram of a $99 \% \mathrm{CH}_{4} / 1 \% \mathrm{~N}_{2}$ stream. 